Cahiers de recherches médiévales

\title{
Encyclopédies et lapidaires médiévaux
}

La durable autorité d'Isidore de Séville et de ses Étymologies

Isabelle Draelants

\section{(2) OpenEdition}

Journals

Édition électronique

URL : https://journals.openedition.org/crm/10682

DOI : $10.4000 / \mathrm{crm} .10682$

ISSN : $1955-2424$

Éditeur

Honoré Champion

Édition imprimée

Date de publication : 10 décembre 2008

ISSN : 1272-9752

\section{Référence électronique}

Isabelle Draelants, "Encyclopédies et lapidaires médiévaux 》, Cahiers de recherches médiévales [En

ligne], 16 | 2008, mis en ligne le 01 décembre 2008, consulté le 15 décembre 2022. URL : http:// journals.openedition.org/crm/10682 ; DOI : https://doi.org/10.4000/crm.10682 


\section{酸 RM}

\section{Encyclopédies et lapidaires médiévaux : la durable autorité d'Isidore de Séville et de ses Étymologies}

Abstract: It is well known that the Etymologiae of Isidore of Seville were wide spread in the Latin medieval West, but the modalities of this diffusion is worth further investigation. Here, we examine its reception on two kinds of naturalistic works: the encyclopaedies and the lapidaries, until and during the XIII ${ }^{\text {th }} C$. The period was the richest and the newest for the encyclopaedic production, where we see that the Etymologiae where used as a "tank» of naturalistic information, but was gradually less considered as a paradigm of the encyclopaedic genre by most of the compilers. His etymological approach, when it still appear, is no more as a way of thinking Nature in the XIII ${ }^{\text {th }}$ C. Furthermore, the auctoritas of Isidore as a naturalist - never as a theologian - is increasingly challenged by Aristotelian science, in the works of Thomas de Cantimpré, Bartholomaeus the Englishmann, and Vincent of Beauvais (Isidore is simply no more quoted by Arnoldus Saxo). In the De mineralibus of Albertus Magnus, Isidore subsists only, when his documentation is not available among other and more recent auctoritates. This article provides as well a rich information about lapidaries between the $I^{s t}$ and the XIII ${ }^{\text {th }} C$., and a comparative chart of the minerals quoted by most lapidarists across this period of time.

Résumé : La large réception des Étymologies d'Isidore de Séville dans l'Occident latin au Moyen Âge est bien connue, mais ses modalités de diffusion méritent d'être mieux étudiées. Leur réception est examinée ici dans deux types d'oeuvres relatives à la nature: les encyclopédies d'abord, les lapidaires ensuite, jusqu'au XIII ${ }^{e}$ s. Celui-ci fut la période la plus riche et la plus originale de la production encyclopédique. Les Étymologies y tinrent lieu de réservoir documentaire pour l'information sur la nature, mais l'oeuvre perdit peu à peu son statut de paradigme du genre encyclopédique. Par ailleurs, sa méthode étymologique, quand elle apparaît encore, ne constitue plus une façon de penser la nature au XIII ${ }^{e}$ s. L'auctoritas d'Isidore comme naturaliste - il est inconnu comme théologien - est aussi contrebalancée progressivement, puis dépassée par la science aristotélicienne, chez Thomas de Cantimpré, Barthélemy l'Anglais et Vincent de Beauvais (chez Arnold de Saxe, il n'est simplement plus cité). Dans le De mineralibus d'Albert le Grand, Isidore subsiste comme source dans les cas où la même matière n'est pas disponible chez d'autres autorités plus récentes. La seconde partie de cet article est jalonnée d'information sur les lapidaires entre le Ir et le XIII siècle, et contient un tableau comparatif des minéraux cités par les principaux lapidaristes durant cette période.

Dans sa dimension épistémologique, la construction de toute encyclopédie est conçue comme un speculum, miroir qui réfléchit le monde dans une vision d'ensemble et construit un rapport analogique entre le discours et les realia ${ }^{1}$. Ancré

${ }^{1}$ Voir E.M. Jonsson, « Le sens du titre Speculum aux XII ${ }^{\mathrm{e}}$ et XIII ${ }^{\mathrm{e}}$ siècles et son utilisation par Vincent de Beauvais", Vincent de Beauvais: Intentions et réceptions d'une ouvre encyclopédique au Moyen Âge. Actes du XIV colloque de l'Institut d'Études Médiévales, organisé conjointement par l'atelier Vincent de Beauvais (A.R.Te.M., Univ. de Nancy II) et l'Institut d'Études médiévales (Université de Montréal), 27-30 avril 1988, éd. M. PaulmierFoucart, S. Lusignan, A. Nadeau, Saint-Laurent - Paris, 1990, p. 11-32.

Cahiers de Recherches Médiévales, 16, 2008 
sur les mots, le savoir encyclopédique médiéval est aussi profondément livresque ; il s'enracine dans une longue tradition qui cumule depuis l'Antiquité les connaissances acquises dans le monde latin ainsi qu'en Orient. Parmi celles-ci, l'enquête sur la natura rerum est primordiale, au point d'être l'éponyme de nombre d'œuvres naturalistes et/ou encyclopédiques, depuis Sénèque jusqu'aux naturalistes du $\mathrm{XV}^{\mathrm{e}}$ siècle, en passant par l'œuvre d'Isidore de Séville (622) ${ }^{2}$, de Raban Maur (c. 840)3 d'Adélard de Bath (avant 1133) ${ }^{4}$ d'Alexandre Nequam (c. 1200) ${ }^{5}$, de Daniel de Morley $(c .1200)^{6}$, de Thomas de Cantimpré (c. 1230-40) ${ }^{7}$, du Pseudo-John Folsham $(c .1250 \text { ? })^{8}$, pour ne parler que des auteurs latins. Mais au-delà de leur intérêt pour la nature des choses, ces ouvrages accordent une importance primordiale à l'auctoritas livrée par la tradition, liée à une attention presque obsessionnelle aux mots et aux noms. Un relatif nominalisme domine donc leur appréhension du réel; à sa base réside, implicitement ou explicitement, le modèle de la démarche étymologique initiée par Isidore de Séville dans ses Etymologiae sive Origines ${ }^{9}$, selon laquelle «L'étymologie est l'origine des vocables» (Etym. I, 29). Cette œuvre emblématique de l'évêque de Séville a par ailleurs joué pour la conception et l'organisation du savoir de certaines encyclopédies médiévales un rôle paradigmatique, bien constaté chez Raban Maur, Thomas de Cantimpré, Barthélemy

\footnotetext{
${ }^{2}$ Isidorus Hispalensis, De natura rerum, édition J. Fontaine, Bordeaux, 1960.

${ }^{3}$ Rabanus Maurus, De universo libri XXII, édition Patrologia latina, t. 111, col. 13-614. Une nouvelle édition est en préparation par William Schipper pour le Corpus Christianorum; le texte provisoire est accessible sur www.mun.ca/rabanus/.

${ }^{4}$ Édition M. Müller, Die Quaestiones naturales des Adelardus von Bath, Münster, 1934 (Beiträge zur Geschichte des Philosophie und Theologie des Mittelalters, 31/2) et Adelard of Bath, Conversations with my Nephew : On the Same and the Different, Questions on Natural Science, and on Birds, éd. C. Burnett, I. Ronca, P. Mantas España, B. Van den Abeele, Cambridge, 1998

5 Édition Th. Wright, Alexander Neckam, De rerum natura, London, 1863 (Rerum Britannicarum Medii Aevi Scriptores, 34), p. 1-354.

${ }^{6}$ Liber de naturis inferiorum et superiorum, Ed. K. Sudhoff, Archiv für Geschichte der Mathematik, der Naturwissenchaften und der Technik, 8 (1917).

${ }^{7}$ Édition H. Boese, Liber de natura rerum, Teil I: Texte, Berlin-New York, 1973. L'apparat critique n'a jamais paru.

${ }^{8}$ Liber de proprietatibus rerum excerptus ex multis auctoribus ou Liber de naturis rerum abreviatus ou Summa de natura et proprietatibus rerum animatarum et inanimatarum. Cf. D. Abramov, «Die moralisierende Enzyklopädie Liber de naturis rerum von Pseudo-John Folsham », Die Enzyklopädie im Wandel vom Hochmittelalter bis zur frühen Neuzeit. Akten des Kolloquiums des Projekts D im SFB 231 (29.11.-1.12.1996), hrsg. Chr. Meier-Staubach, München, 2002 (Münstersche Mittelalter-Schriften, 78), p. 123-54.

${ }^{9}$ Il existe plusieurs éditions critiques, dont W.M. Lindsay, Etymologiarum sive originum libri XX, Oxford, $2^{\mathrm{e}}$ éd., 1957, et l'édition en cours aux Belles-Lettres (Auteurs latins du Moyen Âge), Paris, 1989 pour le livre XII par J. André, 2004 pour le livre XIII par G. Gasparotto, 1981 pour le livre XVII par J. André et 1995 pour le livre XIX par M. Rodriguez-Pantoja Márquez.
} 
l'Anglais (c. 1230-47) $)^{10}$ et Vincent de Beauvais (c. 1240 pour la version bifaria et 1259 pour la version trifaria de son Speculum maius $)^{11}$. En revanche, comme nous le verrons, le nominalisme isidorien n'y joue plus un rôle premier dans l'appréhension des choses.

Chez les encyclopédistes, les Étymologies constituent une source principale et primordiale, essentiellement de deux manières : comme source documentaire et comme modèle de pensée rationnelle fondé sur les mots. Cette oeuvre d'Isidore de Séville offre en effet une documentation de qualité, déjà sélectionnée et organisée en vue d'une diffusion et d'une compréhension aisées. En effet, l'évêque de Séville, officiant dans le royaume wisigothique, était conscient du danger culturel que couraient ses contemporains dans le contexte de la fin d'une civilisation grécoromaine. Il a concentré ses travaux dans l'objectif d'une mise en mémoire, rassemblant sous une forme organisée, accessible aux Chrétiens, l'ensemble des notions didactiques que l'Antiquité avait léguées et qui étaient encore disponibles. D'autre part, Isidore a créé, ou du moins priviliégié, un type de compréhension du monde qui était compatible avec celui de la Chrétienté naissante. Platonicienne, elle est basée sur un principe explicatif unique, tiré de l'enseignement fondamental de l'Antiquité, la grammaire : il s'agissait de révéler un rapport onthologique entre la chose et son nom. Les Étymologies d'Isidore compilent ainsi les sources et organisent la matière en fonction du rapport explicatif entre la chose et son nom. Grâce à l'influence considérable de cette œuvre, l'étymologie devint un mode de pensée typique de la première partie du Moyen Âge, un système d'explication compatible avec le platonisme ambiant, avant que l'avènement de nouveaux textes issus du monde islamique, via les traductions, ne lui substitue peu à peu une appréhension rationnelle plus «sensible» et expérimentale des choses, plus aristotélicienne.

Le mode d'explication étymologique était grammatical, proche de la démarche intellectuelle de l'exégèse littérale (celle du premier sens de l'Écriture, grammatical et historique) qui au cours du XIII ${ }^{\mathrm{e}}$ siècle s'efface au profit d'autres modes d'exposition du texte. En même temps que se délie le lien entre le mot et la chose, la conception symbolique et allégorique de la cosmologie médiévale traditionnelle laisse peu à peu la place, à la fin du XII ${ }^{\mathrm{e}}$ siècle et au début du siècle suivant, à une épistémologie philosophique rationnelle, davantage aristotélicienne. Il est cependant manifeste que les encyclopédistes du deuxième tiers du XIII ${ }^{\mathrm{e}}$ siècle, époque où la production encyclopédique a été la plus riche, oscillent encore entre

\footnotetext{
${ }^{10}$ L'édition de référence reste, pour la plupart des livres, Bartholomaeus Anglicus, De genuinis rerum coelestium, terrestrium et inferarum proprietatibus libri XVIII,... procurante Georgio Bartholdo Pontano a Braitenberg, Frankfurt, apud W. Richterum, 1601 (éd. anast. Minerva GmbH, Frankfurt a.M., 1964), mais une édition critique complète est en cours chez Brepols, s. dir. H. Meyer, B. Van den Abeele et I. Ventura (coord.) : Bartholomaeus Anglicus De proprietatibus rerum, vol. I, Prohemium [éd. H. Meyer], Libri I-IV [éd. 1. I, M.W. Twomey, 1. II, B. Roling, 1. III-IV, R.J. Long], Turnhout, 2007 (De diversis artibus, 78, N.S. 41); I. Ventura, Bartholomaeus Anglicus De proprietatibus rerum, vol. VI, Liber XVII, Turnhout 2007 (De diversis artibus 79, N.S. 42).

${ }^{11}$ Cf. B. Ribémont, De natura rerum. Études sur les encyclopédies médiévales, 1995 (Sapience).
} 
l'un et l'autre, selon le poids platonicien ou aristotélicien de leurs sources littéraires ${ }^{12}$. Quoique les encyclopédistes de ce siècle soient profondément motivés par la prédication, ils adoptent un nouveau mode d'illustration de l'Écriture sainte, qui pour certains d'entre eux constitue désormais plus un point de départ qu'un aboutissement pour décrire la Création. Dans leurs œuvres de compilation, l'exégèse se transforme au profit d'un mode d'énonciation plus descriptif et érudit, qui a pour objectif d'accumuler toutes les informations disponibles sur un phénomène naturel plutôt que de les sélectionner en vue d'un éclairage synthétique.

C'est à un parcours parmi les encyclopédies qui ont jalonné l'influence changeante des Étymologies d'Isidore entre le $\mathrm{VII}^{\mathrm{e}}$ siècle et le XIII ${ }^{\mathrm{e}}$ siècle que cette contribution invite. Cette postérité isidorienne dans un genre littéraire particulier est abordée d'abord d'un point de vue général et illustrée d'exemples tirés de chapitres zoologiques, ensuite via l'examen d'un domaine particulier du monde naturel : la minéralogie, où la postérité du livre XVI des Étymologies a connu une présence continue et de nombreux relais tout au long de cette période.

\section{Quasi-omniprésence des Étymologies dans les encyclopédies médiévales}

D’un point de vue général, les Étymologies d'Isidore sont présentes et influentes dans presque toutes les œuvres admises dans le genre encyclopédique médiéval, protéiforme il est vrai. On sait que Raban Maur a écrit son De universo comme une version allégorique du De natura rerum et des Étymologies. Quatre siècles plus tard encore, Barthélemy l'Anglais, chaque fois que c'est possible, inclut dans ses notices animalières une citation d'Isidore. Dans son De proprietatibus rerum, Isidore reste une source fondamentale, une auctoritas primordiale parmi les sancti qui s'opposent aux theologi dans l'exposition des sources des prologues des chapitres. Le Livre des propriétés des choses termine en effet dans la plupart des manuscrits par une liste des auteurs chrétiens et antiques, caractérisés par les adjectifs sancti, theologi, où apparaît Isidore de Séville aux côtés d'autres pères de l'Eglise comme Ambroise, Jérôme, Augustin, Cassiodore, Grégoire le Grand, mais aussi du traducteur et astrologue du début du XIII ${ }^{\mathrm{e}}$ siècle Michel Scot ${ }^{13}$. La catégorie des philosophi regroupe en revanche les auteurs antiques et leurs traductions par les Arabes, ainsi que les écrivains contemporains.

Quant à Thomas de Cantimpré, comme Barthélemy l'Anglais, il met dans son Liber de natura rerum l'ensemble des autorités citées sous l'égide suprême du père de l'Église Augustin d'Hippone, mais c'est largement aux «philosophes » plutôt qu'aux doctores qu'il donne la parole. Parmi le nombre d'autorités citées, il réserve à Aristote, dit-il dès le prologue, le premier rang parmi les auteurs : primus omnium,

\footnotetext{
${ }^{12}$ Cf. I. Draelants, «La science naturelle et ses sources chez Barthélemy l'Anglais et les encyclopédistes contemporains », Bartholomäus Anglicus, De proprietatibus rerum. Texte latin et réception vernaculaire. Lateinischer Text und volkssprachige Rezeption, éd. B. Van den Abeele - H. Meyer, Turnhout, Brepols, 2006 (De diversis artibus, Coll. de travaux de l'Académie internationale d'Histoire des sciences, t. 74, N.S. 37), p. 43-99.

${ }^{13}$ Peut-on suggérer que la présence de Michel Scot parmi les pères de l'Église serait due à sa participation au Concile de Latran en 1215 ?
} 
le second étant Pline, suivi de Solin et d'Ambroise de Milan ${ }^{14}$. Les cinquième et sixième sont Isidore de Séville et Basile le Grand, tous deux encore Pères de l'Église, latin et grec. Ils interviennent en effet comme naturalistes pour commenter l'œuvre de la Création, celle de l'Hexaemeron. Il semble, si l'on tente des décomptes chiffrés des citations, que Thomas de Cantimpré s'en tienne d'assez près à ce classement a priori des autorités, annoncé dans le prologue du Liber de natura rerum. En suivant l'ordre de fréquence de ses références via des marqueurs - dont la présence n'est pas aussi systématique que chez ses collègues -, on obtient en effet la séquence hiérarchique suivante: Pline l'Ancien, presque à égalité avec Aristote, suivis par la Bible et la Glose, des autorités indéterminées (le " on dit»), Isidore, l'Experimentator, Jacques de Vitry et son Historia orientalis, le Liber rerum, Solin, Ambroise et Augustin ${ }^{15}$. En réalité, ces deux derniers auteurs, Ambroise et Augustin, prennent les premières places au vu du nombre réel de citations empruntées mais souvent non dotés d'un marqueur. En revanche, les autres Pères de l'Église se font plus discrets qu'annoncé, mais Isidore de Séville récolte près de cent trente citations dotées d'un marqueur de source explicite.

C'est chez Vincent de Beauvais que l'utilisation encyclopédique d'Isidore de Séville est la plus représentative. Dans le Grand Miroir, Isidore de Séville apparaît, comme personnage, sous les traits d'un savant, d'un commentateur de l'Écriture, d'un juriste et d'un moraliste, comme l'a montré M. Paulmier-Foucart ${ }^{16}$. Mais le fil rouge de sa présence se tisse tout au long de l'œuvre comme source documentaire.

Beaucoup plus étendu que l'œuvre de ses contemporains Barthélemy l'Anglais et Thomas de Cantimpré, le Speculum maius intègre, à des degrés divers, les œuvres de ses prédecesseurs. La version trifaria, terminée peu avant sa mort, du Speculum naturale, amplifie largement la précédente. Vincent de Beauvais a mené alors une relecture de Pline et d'Isidore, et l'on constate aussi une utilisation directe du Liber lapidum de Marbode (dont il sera question plus bas), l'entrée du De agricultura de Palladius ${ }^{17}$, un emploi intense de Guillaume de Conches. De très nombreux extraits des Étymologies sont répartis dans presque tous les livres du Speculum naturale et du Speculum doctrinale.C'est aussi l'entrée de nombreux auteurs arabes, mais surtout, l'introduction massive d'écrivains imprégnés d'aristotélisme, dont plusieurs dominicains, comme Thomas de Cantimpré, Albert le Grand et Thomas d'Aquin, auxquels s'ajoute Arnold de Saxe. Ainsi, dans le Speculum doctrinale et le Speculum naturale, le Liber de natura rerum de Thomas de Cantimpré est presque intégralement réutilisé au sein des descriptions des animaux, végétaux et animaux du Speculum naturale, dans pas moins de six cents

\footnotetext{
${ }^{14}$ Cf. Prologus, éd. H. Boese, p. 3, 1. 16-29.

${ }^{15}$ Nous avons publié la liste des autorités présentes dans le Liber de natura rerum dans : «La question ou le débat scolastique comme forme du discours scientifique dans les encyclopédies naturelles du XIII ${ }^{\mathrm{e}}$ siècle: Thomas de Cantimpré et de Vincent de Beauvais ", Scientiarum historia, (2005/2), p. 1-29 (annexes), mis en ligne_www.univnancy2.fr/MOYENAGE/VincentdeBeauvais/Philosophienaturelle.htm\#2

${ }^{16}$ Cf. M. Paulmier-Foucart, «Les Étymologies d'Isidore de Séville dans le Speculum maius de Vincent de Beauvais », L'Europe héritière de l'Espagne wisigothique, Madrid, 1992, (CCV 35), p. 269-83.

${ }^{17}$ Cent trente-quatre chapitres inspirés de son œuvre seront introduits dans la trifaria.
} 
passages de longueur variable ${ }^{18}$; toute la matière de la partie minéralogique du $D e$ floribus rerum naturalium d'Arnold de Saxe $(\text { c. 1225-45 })^{19}$ se retrouve quant à elle dispersée dans le livre VIII du Speculum naturale, et des citations du De proprietatibus rerum de Barthélémy se révèlent glissées sous le marqueur actor, sous couvert duquel Vincent de Beauvais expose des opinions qu'il adopte.

Les livres consacrés à la description de la nature dans le Speculum naturale et dans le Doctrinale de Vincent de Beauvais révèlent une pondération des auctoritates assez différente de la hiérarchie des sources annoncée par l'imposant prologue ${ }^{20}$. En effet, le Libellus apologeticus place les textes sacrés en premier lieu, et les philosophes en troisième place, juste avant les textes apocryphes. Dans le domaine naturaliste, l'autorité philosophique - c'est-à-dire la littérature profane des savants antiques - vient nécessairement compléter ou supplanter les textes sacrés. En cette matière, la position double d'Isidore était idéale, puisqu'il émarge à la patristique, mais transmet également des ouvrages exclusivement philosophiques. Pour estimer le poids des autorités, on peut se fier à l'introduction des marqueurs de citations qui sont autant de références bibliographiques médiévales, car ils témoignent de la volonté de Vincent de Beauvais de s'intéresser à un auteur et ne dépendent pas du volume de l'œuvre de ce dernier. Si l'on examine le texte de cette manière, mille deux cents extraits des Étymologies nourrissent les Speculum naturale et doctrinale, à égalité avec Aristote, et derrière l'Historia naturalis de Pline l'Ancien, ce qui fait d'Isidore la seconde autorité dans le domaine de l'exploration de la nature.

Ainsi, le classement des autorités annoncé déjà par Thomas de Cantimpré correspond assez bien aussi à la réalité de la documentation chez Vincent de Beauvais, où Pline surpasse de loin, quantitativement, toutes les autres autorités, mais où il est suivi aussitôt par les Étymologies d'Isidore et le Liber de natura rerum de Thomas de Cantimpré. Isidore apparaît donc quantitativement dans la version trifaria (1259) du Naturale et du Doctrinale, parmi les dix auteurs les plus cités ${ }^{21}$ :

\footnotetext{
${ }^{18}$ Sur les apports de Thomas de Cantimpré au Speculum, v. B. Roy, «La trente-sixième main : Vincent de Beauvais et Thomas de Cantimpré », Vincent de Beauvais: Intentions et réceptions d'une œuvre encyclopédique au Moyen Âge (...), p. 241-51.

${ }_{19}$ Édition E. Stange, Die Encyklopädie des Arnoldus Saxo, zum ersten Mal nach einem Erfurter Codex, Erfurt, 1904-1906; 1907 (Beilage zur Jahresbericht d. Gymnasium Erfurt). Ed. en cours par I. Draelants et édition des prologues dans I. Draelants, «Une mise au point sur les œuvres d'Arnold de Saxe, $1^{\mathrm{e}}$ partie», et " $2^{\mathrm{e}}$ partie», Bulletin de Philosophie Médiévale, 34 (1992), p. 164-80, et 35 (1993), p. 130-49. Édition d'extraits dans I. Draelants, Un encyclopédiste méconnu du XIII siècle: Arnold de Saxe. Oeuvres, sources, réception, Louvain-la-Neuve, 2000 (thèse d'histoire).

${ }^{20}$ Édition S. Lusignan, Préface au Speculum maius de Vincent de Beauvais : réfraction et diffraction, Montréal-Paris, 1979. Traduction intégrale dans M. Paulmier-Foucart, avec la coll. de M.-Ch. Duchenne, Vincent de Beauvais et le Grand Miroir du monde, Paris, 2004 (Témoins de notre Histoire).

${ }^{21}$ Nos dénombrements sont effectués sur le texte de l'édition de Douai, 1624, où des citations de Pline ont été ajoutées ou allongées par les éditeurs. Nous considérons comme une seule citation un texte précédé d'un marqueur de source du type Isidorus in libro..., même si le texte qui suit le marqueur est composé de plusieurs extraits. Le nombre total de citations précédées
} 


\begin{tabular}{|l|c|c|}
\hline \multicolumn{1}{|c|}{ Nom d'auteur ou d'œuvre } & $\begin{array}{c}\text { Speculum naturale } \\
8900[276]\end{array}$ & $\begin{array}{c}\text { Speculum doctrinale } \\
1099[17]\end{array}$ \\
\hline Plinius & $1721[190]$ & 78 \\
\hline Isidorus & $946[4]$ & 143 \\
\hline Ex libro de natura rerum & 671 & 78 \\
\hline Aristoteles & $626[15]$ & 186 \\
\hline Avicenna & $628[24]$ & 26 \\
\hline Actor & $495[13]$ & \\
\hline Dioscorides & 471 & $65[1]$ \\
\hline Palladius & $383[4]$ & \\
\hline Constantinus & $282[4]$ & \\
\hline Platearius & 265 & \\
\hline Albertus [Magnus, Summa de homine] & $250[18]$ & \\
\hline
\end{tabular}

En-dehors de cette utilisation massive des Étymologies, Isidore apparaît une seule fois comme polygraphe, dans la partie historique du Grand miroir, le Speculum historiale, où quatre chapitres du livre XXXIII sont consacrés à sa vie et à son œuvre (c. 31-34). Vincent de Beauvais ne disposait pas d'une biographie de l'archevêque hispanique, il emprunte donc les dires du chroniqueur du $\mathrm{XI}^{\mathrm{e}}$ siècle Sigebert de Gembloux et constitue, comme il le peut - sous la référence actor qui l'auto-désigne comme auteur -, une bibliographie des ouvrages d'Isidore. Vincent termine cette liste par extat apud nos, ce qui signifie qu'il pouvait disposer de ces livres dans la bibliothèque qu'il fréquentait. Vincent de Beauvais ajoute à la notice bio-bibliographique, aux chapitres 32-34, trois courts chapitres d'extraits des Synonymes. Il recourt aussi au savoir d'Isidore comme géographe, dans le livre I de l'Historiale, aux chapitres 62-85 et 92-95, aux côtés de rares extraits de Solin et de Pierre Comestor, mais aussi à la suite d'extraits du De proprietatibus rerum de Barthélemy l'Anglais adoptés sous le marqueur actor. En revanche, Vincent de Beauvais ne connaît ni les œuvres historiques, ni les oeuvres théologiques d'Isidore; il y a tout lieu de croire que les extraits qu'il en retient viennent d'un florilège spirituel et non d'un travail original de collecte.

Dans le Liber apologeticus (prologue), Isidore est cité cinq fois, notamment dans le chapitre 7, où on lit un panégyrique de la connaissance, Apologia de universitate scientiarum, où Vincent se présente comme un compilateur aux prédécesseurs illustres, parmi lesquels Isidore ${ }^{22}$ :

d'un marqueur, pour chaque Speculum, figure à la première ligne. Les chiffres entre crochets sont des citations à rétablir (marqueur manquant, par exemple).

22 «On pourrait me trouver présomptueux d'oser parler de toutes les sciences et de tous les arts, moi qui ne suis suffisamment savant en aucune matière, mais mon propos n'est pas d'en 


\begin{abstract}
Ad hoc autem ipsum nostrorum studiis provocatus sum, Isidori videlicet Hispalensis, et Hugonis atque Richardi Parisiensis. Quorum primus in libro Etymologiarum, inter caetera de quibus agit, etiam de unaquaque scientia pauca breviter tangit. Secundus in libro Didascalicon scientiam generaliter dividit, singularumque materiam breviter describit. Et tertius, qui sic dicitur, in libro Excerptionum idem facit.
\end{abstract}

«Et j'ai été conforté dans mon projet par les travaux de mes prédecesseurs, à savoir Isidore de Séville, qui a touché à chacune des sciences dans le Livre des Étymologies, et Hugues et Richard de Paris, qui ont proposé une division des sciences dans le Didascalicon et le Liber exceptionum. »

Le choix des modèles du Speculum maius est donc clair: les Étymologies pour leur caractère encyclopédique, comme paradigme, et l'organisation des connaissances d'après la science victorine (qui inclut la théologie, les sciences logiques, pratiques - mécaniques - et théoriques).

Plus loin, au c. 12 du prologue, Isidore est évoqué comme père de l'Église, parmi les auctoritates qui hiérarchisent le discours; il se trouve au premier rang des auctoritates, parmi les décrétales pontificales, les canons des conciles et les docteurs canonisés. Il avait été déjà question de lui sur ce mode dans le premier chapitre, en compagnie des quatre grands pères de l'Église romaine, quand Vincent de Beauvais expliquait pour quelles raisons il était très attentif à l'attribution correcte des citations à un auteur. Au chapitre $8 \mathrm{du}$ prologue, il est question des matières de sciences naturelles, qui ne sont plus des questions de foi, et où l'autorité a moins d'importance, celle d'un auteur étant contrebalancée par celle d'un autre :

C. 8, Apologia de dictis philosophorum et poetarum: Venena quoque serpentum quidam frigida esse dicunt, ut Isidorus, quidam vero calida, ut Avicenna. Sed quoniam in istis et in aliis huiusmodo utralibet pars contradictioni absque fidei nostre periculo potest credi vel discredi... lectoris arbitrio relinquendum cuius sententiae potius debeat adhaerere.

«Je n'ignore pas qu'il y a des données contradictoires dans les extraits que j'ai faits... Aristote et Sénèque ne sont pas d'accord sur la nature de l'air ; Isidore dit que le venin des serpents est froid, Avicenne prétend qu'il est chaud. tout cela n'est pas matière de foi, et le lecteur est libre de se faire une opinion. $»^{23}$

Pour ce qui touche à la nature des choses, l'autorité d'Isidore n'apparaît donc ni plus grande, ni moindre que celle des Grecs, des Latins ou des Arabes, même si la connaissance de cette nature des choses est indispensable à celle de l'Écriture. De la même façon, les livres des docteurs de l'Église n'épuisent-ils pas toute la matière :

traiter comme un auteur, je fais seulement des extraits, je construis un compendium utile à la mémoire, mis en ordre.» Cité par M. Paulmier-Foucart, "Les Étymologies d'Isidore de Séville dans le Speculum maius » (op. cit.), p. 269, dont les principales conclusions générales sont reprises ici sur l'utilisation d'Isidore dans le Speculum maius.

${ }^{23}$ Trad. M. Paulmier-Foucart. 
dans le domaine de la science naturelle, les libri philosophorum sont nécessaires aussi :

C. 18 , Retractatio prime partis : Porro investigando naturam, cuius notitia valet, ut supra dictum est, etiam ad expositionem sacrarum scripturarum, non solum, inquam, in nostrorum libris, sicut Ambrosii, Basilii, Isidori et aliorum quorumdam, verum et in libris philosophorum...

Il arrive par ailleurs, dans le Speculum doctrinale, que certains titres de chapitre soient empruntés aux Étymologies ${ }^{24}$. Mais les matières auxquelles est appliqué ce traitement sont traditionnelles et ne font pas partie du système des connaissances universitaires, et n'ont pas encore connu de renouvellement au XIII siècle, à l'exception notable de la médecine. Pour le reste, Isidore n'est donc plus le fondement d'une classification des matières.

Du point de vue de l'utilisation de la documentation offerte par Isidore, ce sont donc les Étymologies qui sont utilisées presque exclusivement dans le Speculum maius, grâce à la richesse et à la qualité de leur documentation sur la nature. Pourtant, un des livres des Étymologies est totalement absent des citations que fait Vincent de Beauvais: le livre X, De vocabulis, c'est-à-dire le dictionnaire. La lexicographie d'Isidore ne serait-elle donc pas importante aux yeux du prolixe compilateur dominicain du milieu du XIII ${ }^{\mathrm{e}}$ siècle ? Pourtant, ce dernier possède son propre dictionnaire, présenté à la fin du livre I du Speculum doctrinale, au chapitre 45 , avant l'exposé sur les sciences du langage ; mais très peu de mots sont communs avec le dictionnaire d'Isidore. Vincent de Beauvais ne donne que très exceptionnellement l'origine du mot difficile et se contente de sa signification par équivalence, à la manière d'un glossaire. Chez Vincent de Beauvais donc, même si, au fil du recopiage de citations d'Isidore, des Étymologies sont encore reproduites, la démarche étymologique en rapport avec l'ontologie de la chose n'est plus un principe d'explication nécessaire.

Dans le domaine de l'histoire, de la théologie, et pour la plus grande partie de la grammaire, Isidore est très peu ou pas utilisé dans le Speculum maius. Pour les sujets de l'arithmétique et la théorie des nombres, on peut noter que Vincent de Beauvais, dans le Speculum doctrinale, choisit à la fois de rejeter Isidore et d'y renvoyer en même temps qu'à Boèce, dans l'idée d'éviter de rentrer dans les détails techniques abondants ${ }^{25}$.

Ce n'est donc pas dans les différents domaines de l'histoire ecclésiastique, de l'histoire humaine, des règnes, des peuples, de la grammaire et des autres arts libéraux du trivium, ni même des livres religieux, des anges et des attributs divins que les Étymologies d'Isidore ont laissé la trace la plus remarquable chez les

\footnotetext{
${ }^{24}$ M. Paulmier-Foucart, «Les Étymologies d'Isidore de Séville dans le Speculum maius » (op. cit.), p. 280.

${ }^{25}$ Artis huius species sunt sex, scilicet additio, substracio duplicatio, dimidatio, multiplicatio, divisio, de quibus singulis propriae regulae datae sunt in algorismo, quas et plures alias numeri divisiones et proportiones, de quibus in Isidoro et Boetio, ad praesens brevitatis causa praetermitto. Speculum doctrinale, XVI, 9, à la fin d'un long passage Actor sur le comput et le calcul. Cité par M. Paulmier-Foucart, «Les Étymologies d'Isidore de Séville dans le Speculum maius » (op. cit.), p. 281.
} 
encyclopédistes du XIII ${ }^{\mathrm{e}}$ siècle, mais comme réservoir de documentation dans le domaine de prédilection de ces encyclopédistes : la science naturelle. Ce sont ainsi, très largement, les livres IV, sur la médecine, le livre XI, sur l'homme et ce qui s'y rapporte, le livre XII, sur la nature des animaux, le livre XVI, sur les pierres et les métaux, et le livre XVII, sur les plantes (De rebus rusticis), qui sont amplement utilisés, à au moins $75 \%$ de leur contenu. Les autres domaines sont soit abandonnés, soit remplacés par un autre discours ${ }^{26}$. Ce constat vaut aussi pour Thomas de Cantimpré et Barthélemy l'Anglais, représentants comme Vincent de Beauvais des ordres mendiants.

Ce constat dans des encyclopédies très diffusées et à la volonté manifeste d'ouverture sur toutes les sciences peut être complété par un exemple issu d'un ordre religieux plus traditionnel, comme Konrad de Mure (1210-1281), rector puerorum d'une abbaye bénédictine. En dépit d'une oeuvre principalement théologique, il s'intéressa aux listes de minéraux et d'animaux dans son Fabularius en prose $^{27}$ et écrivit un De naturis animalium qui contient un résumé de l'ancien testament, un lexique de Abas à Zoroastes, et trois listes alphabétiques de minéraux, plantes et arbres. Sa documentation, accueillante à Isidore de Séville et au Physiologus, garde un caractère très conservateur et correspond davantage au patrimoine littéraire monastique qu'à une curiositas ouverte vers l'extérieur représentée dans les ordres mendiants.

En ce qui concerne la science naturelle, Isidore a donc gardé une place considérable dans la plupart des grandes encyclopédies du XIII ${ }^{\mathrm{e}}$ siècle. Le fait n'est pas étonnant dans la mesure où le genre des compilations encyclopédiques se nourrit en effet d'abord des compilations antérieures. Pline, Solin, le Physiologus, Isidore, l'Aviarium d'Hugues de Fouilloy cher à Thomas de Cantimpré, l'herbier de «Macer floridus » (peut-être écrit par Odon de Meung, $\mathrm{XI}^{\mathrm{e}}$ siècle), sont autant d'autorités encyclopédiques traditionnelles, auxquelles on peut ajouter Palladius pour l'agriculture. Il en va de même, dans une moindre mesure, pour l'utilisation du De natura rerum et le De computo de Bède, l'œuvre homonyme de Raban Maur et l'Imago mundi d'Honorius Augustodunensis. Avec les Étymologies d'Isidore, ces œuvres nourrissent de manière essentielle et prééminente celles de Thomas, Barthélemy, Vincent. Cependant, la situation n'est pas comparable chez le plus aristotélicien des encyclopédistes de cette génération: Arnold de Saxe, qui n'insère aucune citation d'Isidore de Séville ou de ces naturalistes latins traditionnels dans son De floribus rerum naturalium, pour une raison annoncée dès le prologue. En effet, il est résolu, dit-il, à ne puiser que dans les philosophi moderni ${ }^{28}$, titre auquel ne peut assurément plus prétendre Isidore. Son encyclopédie est en effet fondée sur des causalités naturelles à la mode aristotélicienne, et plus seulement sur une hiérarchie des éléments naturels.

\footnotetext{
${ }^{26}$ Quelques exemples dans Ibidem, p. 276-77.

${ }^{27}$ Konrad de Mure a été rector puerorum chez les Bénédictins de Zurich de 1244 à 1271, après des voyages à Paris et à Bologne. Cf. A.P. Orban (éd.), Conradus von Mure, De naturis animalium, Heidelberg, 1989, ici notamment p. 11-12.

${ }^{28}$ Cf. I. Draelants, «Introduction à l'étude d'Arnoldus Saxo et aux sources du De floribus rerum naturalium », Die Enzyklopädie im Wandel (op. cit.), p. 85-121 et I. Draelants, «La science naturelle et ses sources » (op. cit.).
} 
Chez Isidore et ses héritiers intellectuels qui partagent une vision symbolique du monde, la nature reflètait la volonté divine et le plan était orienté hiérarchiquement et verticalement. Les realia n'y étaient donc pas l'objet premier de la connaissance, comme chez Aristote, mais seulement un moyen de l'atteindre, dans une vision verticale de l'univers. C'est cette cosmologie en accord avec la culture générale occidentale traditionnelle qui survit dans le Liber floridus de Lambert de Saint-Omer ou le De naturis rerum d'Alexandre Nequam. Elle reste trente ans plus tard sous-jacente chez Barthélemy l'Anglais, Thomas de Cantimpré. L'organisation de la matière y est d'ordre théologique, puisqu'elle se décline sur l'Hexahaemeron ${ }^{29}$. Même dans les encyclopédies en langue vernaculaire, cette organisation traditionnelle subsiste en partie après l'arrivée de l'aristotélisme.

2. Un exempletypique d'utilisation encyclopédique: notices animalières chez trois grands encyclopédistes du XIII siècle

On connaît aujourd'hui assez bien les méthodes de travail des encyclopédistes et celle des florilèges thématiques et alphabétiques : l'originale est dépecé en citations reclassées ensuite d'après plusieurs systèmes (vertus et vices, classification des sciences, jours de la création, éléments physiques, ordre alphabétique...). Dans les notices relatives aux animaux, la technique de compilation adoptée par Thomas de Cantimpré, Barthélemy l'Anglais et Vincent de Beauvais est commune : la plupart du temps, il n'y a pas vraiment abréviation, mais extraction de citations, et concentration de l'information sous forme de juxtaposition de passages coupés, sans modification stylistique. Ce système implique le plus souvent que les citations internes d'auteurs antiques qu'Isidore lui-même avait introduites ne soient pas conservées par les encyclopédistes du XIII ${ }^{\mathrm{e}}$ siècle, probablement parce que la mémoire s'en était perdue.

Pour Thomas, Barthélemy, Vincent, on peut avancer avec une quasi-certitude que les extraits des Étymologies sont faits de première main. Un des procédés de citation des trois encyclopédistes consiste à annoncer les notices par une courte introduction isidorienne généraliste sur une question, puis à revenir à d'autres originalia (p. ex. Aristote et des auteurs de langue arabes), c'est-à-dire à des sources multiples, et à terminer par une très brève synthèse tirée des mots d'Isidore. Dans d'autres cas, le texte n'est plus coupé en petites entités, mais cité en séquences, quasiment sans coupure, sans enchevêtrement de sources, mais dans une juxtaposition de longs extraits. C'est le cas, par exemple, quand Vincent de Beauvais reprend des extraits des Étymologies sur les arts mécaniques.

Ceci peut être illustré par les notices sur le rhinocéros, la licorne et de l'éléphant, abordés ensemble dans les Étymologies au livre animalier XII, mais aussi aux livres XIV, XV, XVI à l'occasion du traitement de certains lieux géographiques

\footnotetext{
${ }^{29}$ Cf. M. Paulmier-Foucart, «Une des tâches de l'encyclopédiste: intituler, les titres des chapitres du Speculum naturale de Vincent de Beauvais », L'enciclopedismo medievale, éd. M. Picone, Ravenna, 1994, p. 147-62 et Eadem, «Le plan et l'évolution du Speculum maius de Vincent de Beauvais : de la version bifaria à la version trifaria », Die Enzyklopädie im Wandel (op. cit.), p. 245-68.
} 
ou de l'ivoire ${ }^{30}$. Les encyclopédistes du XIII ${ }^{\mathrm{e}}$ siècle en retiennent seulement les citations du livre XII, que voici.

(c. $2, \S 12)$ Rhinoceron a Graecis vocatus. Latine interpretatur in nare cornu. Idem et monoceron $^{31}$, id est unicornus ${ }^{32}$, eo quod unum cornu in media fronte habeat pedum quattuor ita acutum et validum ut quidquid inpetierit, aut ventilet aut perforet.

Nam et cum elephantis saepe certamen habet ${ }^{33}$, et in ventre vulneratum prosternit. Tantae autem esse fortitudinis ut nulla venantium virtute capiatur; sed, sicut asserunt qui naturas animalium scripserunt, virgo puella praeponitur, quae venienti sinum aperit, in quo ille omni ferocitate deposita caput ponit, sicque soporatus velut inermis capitur. Elephantum Graeci a magnitudine corporis vocatum putant, quod formam montis praeferat; graece enim mons lophos $^{34}$ dicitur. Apud Indos autem a voce barro vocatur; unde et vox eius barritus, et dentes ebur. Rostrum autem proboscida dicitur ${ }^{35}$, quoniam illo pabulum ori admovet; et est angui similis, vallo munitus eburno.

( $(15-16)$ Nam hoc genus animantis in rebus bellicis aptum est; in eis enim Persae et Indi ligneis turribus conlocatis, tamquam de muro iaculis dimicant. Intellectu autem et memoria multa vigent. Gregatim incedunt ${ }^{36} ;$ motu, quo valent, salutant ${ }^{37}$; murem fugiunt; aversi count; quando autem parturiunt, in aquis vel insulis dimittunt fetus propter dracones, quia inimici sunt et ab eis inplicati necantur; biennio autem portant fetus, nec amplius quam semel gignunt nec plures, sed tantum unum; uivunt [autem] annos trecentos. Apud solam Africam et Indiam elephanti prius nascebantur; nunc sola eos India gignit.

${ }^{30}$ Les extraits non repris par les encyclopédistes pour les notices sur l'éléphant et le rhinocéros se trouvent en XIV, c. $3, \S 5$; c. $5, \S 12$ et $\S 15$; c. $6, \S 12$, et en XV, c. $1, \S 18$ et c. $5, \S 18$, à propos de l'ivoire (ebur).

${ }^{31}$ Gregorius, Moralia, XXXI, c. 10, c. 13.

${ }^{32}$ Pline, Naturalis historia, VIII, c. 20-21, dit que le monoceros est différent du rhinocéros et de l'unicorne (XI, c. 46). Il s'inspire là d'Aristote, Historia animalium, II, c. 1. Pline ajoute qu'on en voit souvent à Rome, mais qu'il n'est pas possible de le prendre vivant. Solin reprend les dires de Pline (Vivus, inquit, non venit in hominum potestatem), en variant les mesures : pedum quatuor (chez Pline: cubitorum duorum; cubiti unius). Chez Elien, De naturis animalium, IV, c. 52, De asinis Indicis, on trouve la mesure suivante: sesquicubiti. Pline estime que le monoceros ne peut pas être «l'âne indien».

${ }^{33}$ Le combat du rhinocéros avec l'éléphant est repris chez Pline, Solin, Elien, Diodore de Sicile, Strabon.

${ }^{34}$ Lophos signifie en effet « mont » en grec.

${ }^{35}$ Ambroise, Hexaemeron, IX.

${ }^{36}$ Pline, Naturalis historia, VIII, c. 5.

${ }^{37}$ Solin, Solis exortus motibus, quibus possunt, salutant. 
(c. 4, § 5) Innoxius autem est a venenis, sed ideo huic ad mortem faciendam venena non esse necessaria, quia si quem ligarit occidit. A quo nec elephans tutus est sui corporis magnitudine.

Vincent de Beauvais et Barthélemy l'Anglais citent les extraits ci-dessus à peu près intégralement, tandis que Thomas de Cantimpré ne reprend chez Isidore que ce qu'il n'a pas trouvé chez Pline, souvent plus explicite, ni chez Solin. Thomas a en effet davantage recours aux exempla ou aux historiettes que ses congénères, ce qui explique sa préférence pour le peu fiable Solin.

La longueur des notices animalières est sensiblement différente chez chaque auteur, c'est pourquoi nous en avons souvent résumé la teneur, dans le tableau qui suit: Vincent de Beauvais est à son habitude beaucoup plus prolixe et découpe la matière en chapitres thématiques et calibrés. Monique Paulmier-Foucart a montré que le texte des Étymologies était chez Vincent de Beauvais apparenté à deux manuscrits de la fin du XII ${ }^{\mathrm{e}}$ siècle provenant du fonds de Notre-Dame (Paris, B.n.F. lat. 17876) et de Saint-Germain-des-Prés (B.n.F. lat. 11864) ${ }^{38}$. Dans l'édition du De proprietatibus rerum de Frankfurt en 1601, le texte d'Isidore a été copié à partir d'un modèle très proche de celui qui a servi de base à la Patrologie latine. Par ailleurs, le choix de Barthélemy est beaucoup plus patristique que celui de ses congénères. Ses sources, pour ces deux notices, sont également moins variées que celles de son contemporain Thomas de Cantimpré, et d'autant moins que celles du Speculum naturale, qui reprend intégralement son Liber de natura rerum et le mêle aux sources antérieures sur le même sujet.

\begin{tabular}{|c|c|c|}
\hline $\begin{array}{l}\text { TC, LDNR IV, De animalibus } \\
\text { quadrupedibus, c. } 33, \text { de } \\
\text { elephante (2181 mots) }\end{array}$ & $\begin{array}{l}\text { BA, DPR XVIII, c. } \\
\text { 41, De elephante } \\
\text { (540 mots) }\end{array}$ & $\begin{array}{c}\text { VB, SN, XIX, De bestiis. } \\
\text { (2897 mots) }\end{array}$ \\
\hline $\begin{array}{l}\text { Elephantes, ut dicit IACOBUS, } \\
\text { animalia sunt robusta viribus et } \\
\text { corpore magna. } \quad(. . .) \\
\text { [description physique] } \\
\text { ARISTOTILES: [nez] Et hec est } \\
\text { ratio (AMBROSIUS) : [porte de } \\
\text { lourdes charges et se sert de sa } \\
\text { trompe] Liber RERUM: [aime le } \\
\text { vin] IACOBUS: [utilisation par } \\
\text { les Perses et les Indiens dans la } \\
\text { guerre, surmontés de tours en } \\
\text { bois] ut ait AMBROSIUS, } \\
\text { [armées; cri utilisé pour } \\
\text { effrayer] Magnus ALEXANDER, } \\
\text { ut scribitur in eius epistola, } \\
\text { pugnaturus contra Indos ereas } \\
\text { statuas prunis ardentibus } \\
\text { impleri iussit. Putantes autem } \\
\text { elephantes statuas illas homines }\end{array}$ & 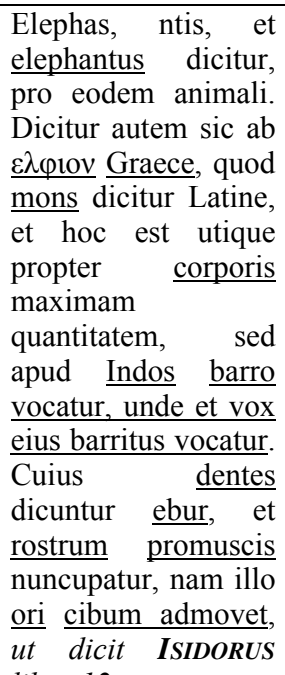 & $\begin{array}{l}\text { c. 38, De elephante. } \\
\text { ISIDORUS. Elephantem greci a } \\
\text { magnitudine corporis vocatum } \\
\text { putant, eo quod formam montis } \\
\text { preferat. Grece enim mons elephon } \\
\text { dicitur, apud indos autem a voce } \\
\text { barro vocatur, unde et vox eius } \\
\text { barritus et dentes eius ebur. } \\
\text { SOLINUS. [deux sortes; mangent les } \\
\text { troncs et les pierres, ainsi que les } \\
\text { fruits des palmiers; craints par les } \\
\text { Maures; n'aiment pas le froid; se } \\
\text { guérissent par une huile; dos dur, } \\
\text { ventre mou, pas de poils] } \\
\text { ARISTOTELES. [certains boivent de } \\
\text { l'huile; du vin, utilisé pour les guérir } \\
\text { aussi; animal fluvial; aspire l'eau; ne } \\
\text { peut pas se baigner longtemps à } \\
\text { cause de son poids; grandeur du }\end{array}$ \\
\hline
\end{tabular}

${ }^{38}$ M. Paulmier-Foucart, "Les Étymologies d'Isidore de Séville dans le Speculum maius », p. 274. 


\begin{tabular}{|c|c|c|}
\hline 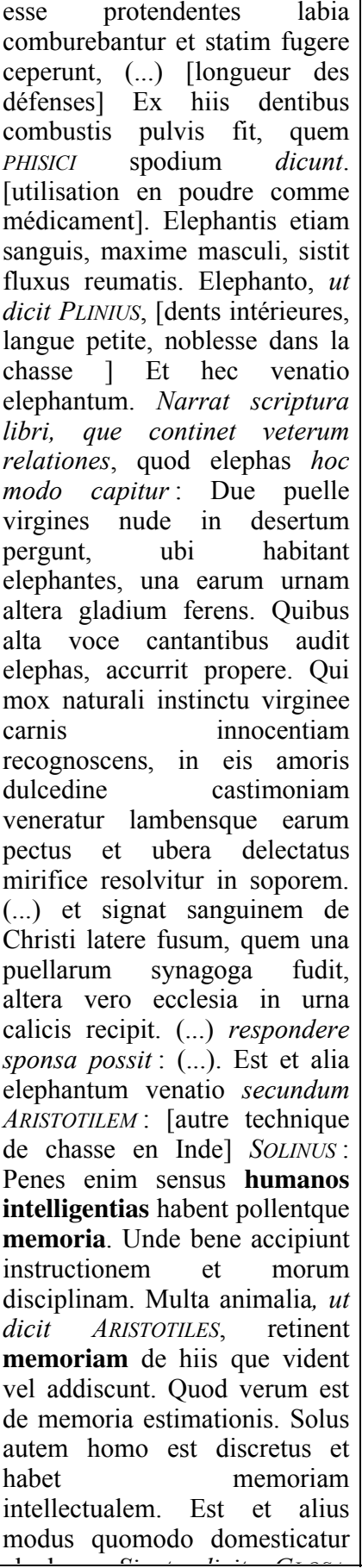 & 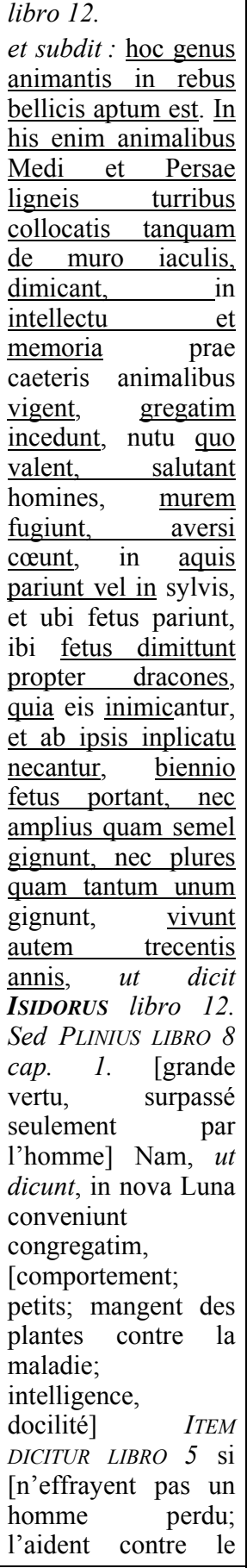 & 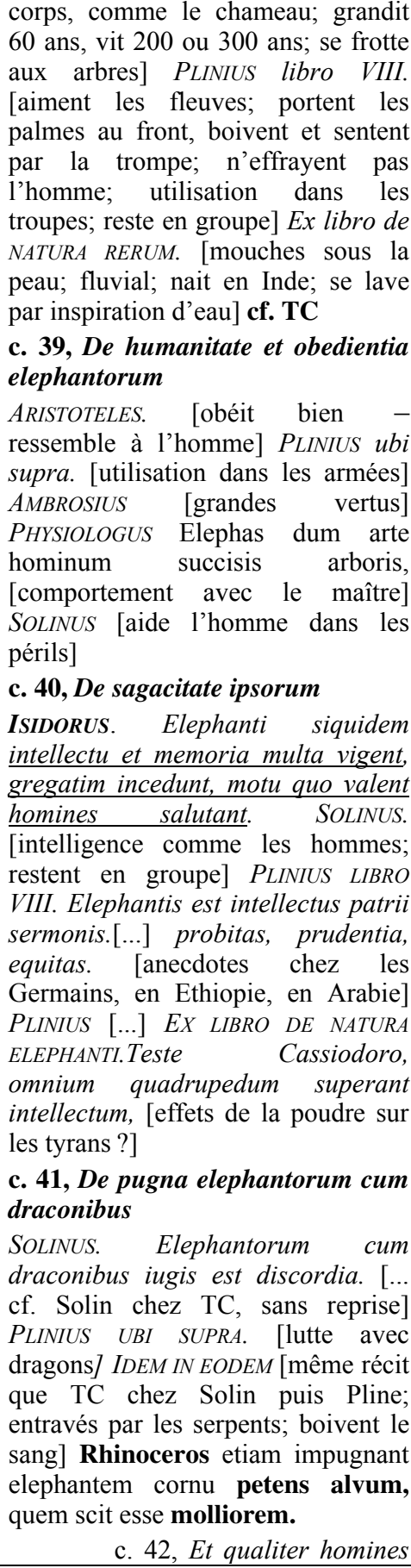 \\
\hline
\end{tabular}




\begin{tabular}{|c|c|c|}
\hline 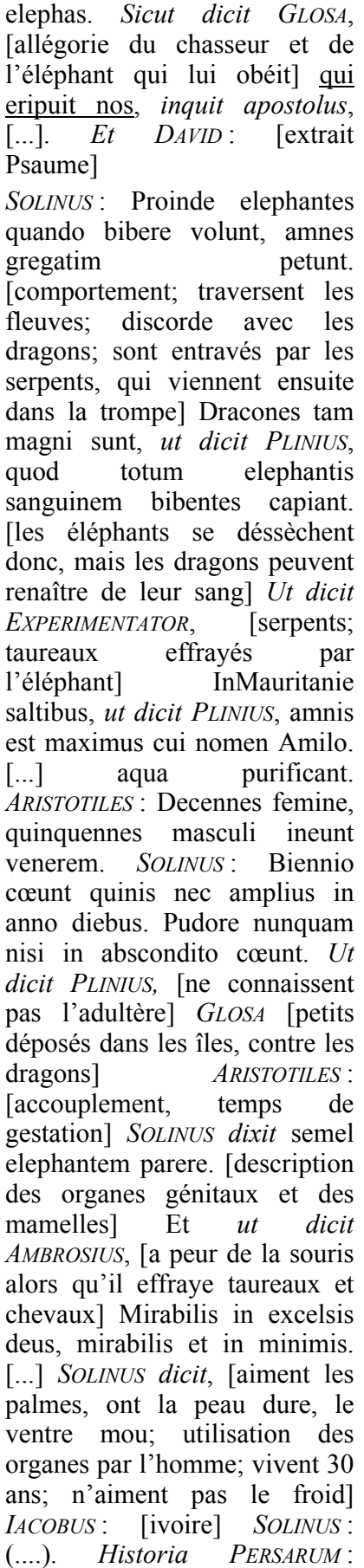 & $\begin{array}{l}\text { dragon; protègent } \\
\text { leurs petits contre } \\
\text { l'homme] } \\
\text { LIBRO } 8 \text { ITEM } \\
\text { [coopèrent et restent } \\
\text { en groupe; laissent } \\
\text { passer les petits } \\
\text { devant dans les } \\
\text { fleuves], UT DICIT } \\
\text { IBIDEM. [pudeur } \\
\text { admirable; } \\
\text { accouplement à } 50 \\
\text { ans pour le mâle, à } \\
\text { 10 pour la femelle; } \\
\text { deux ans de } \\
\text { gestation], } \\
\text { DICUNT, (...) } u t \text { DICIT } \\
\text { IDEM. } \\
\text { [utilisation de tours } \\
\text { en bois par les } \\
\text { Indiens] ITEM CAP. } \\
\text { 40. [mangent les } \\
\text { fruits du palmier; } \\
\text { lutte avec les } \\
\text { dragons; dragons } \\
\text { boivent leur sang] ut } \\
\text { patet supra eodem, } \\
\text { ubi agitur de } \\
\text { dracone, vide ibi. }\end{array}$ & 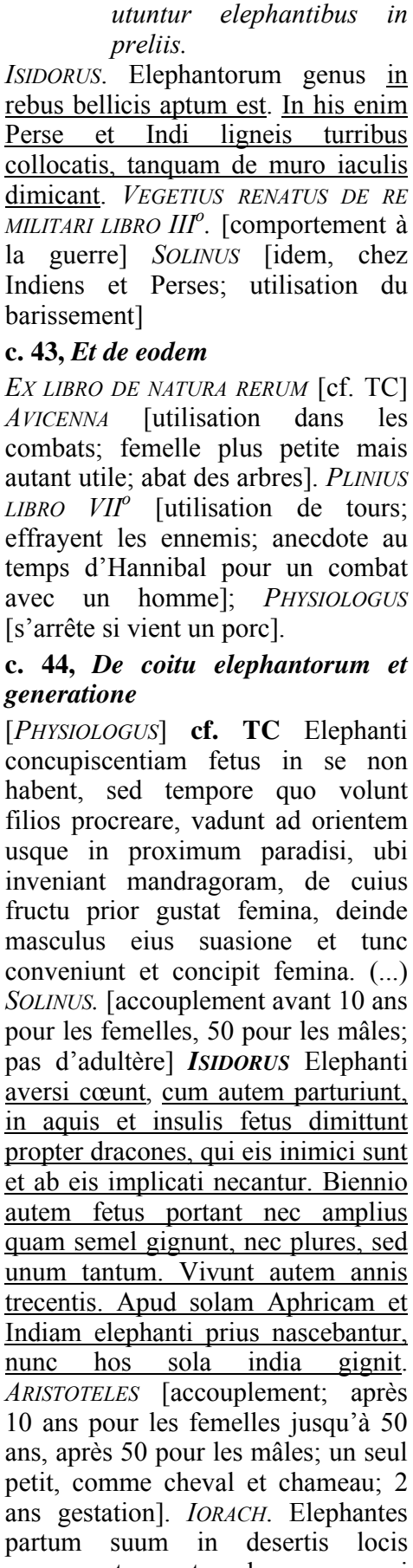 \\
\hline
\end{tabular}




\begin{tabular}{|c|c|}
\hline $\begin{array}{l}\text { (anecdote). SOLINUS: [mouches } \\
\text { sous la peau] ARISTOTILES : } \\
\text { [position assise] AMBROSIUS : } \\
\text { [idem et adossement sur un } \\
\text { arbre, au risque de le casser] ut } \\
\text { ait AMBROSIUS [comportement } \\
\text { des chasseurs à cette occasion]. } \\
\text { LIBER RERUM: [particularité des } \\
\text { positions et des os]. Ut dicit } \\
\text { EXPERIMENTATOR, [plie les pieds } \\
\text { postérieurs comme les hommes; } \\
\text { ongles] ARISTOTILES: Et } \\
\text { notandum, quod contra omnia } \\
\text { animalia terre intestina eius } \\
\text { disposita et formata sunt. } \\
\text { [...estomac, foie, intestin, bile; } \\
\text { mangent de la terre et en } \\
\text { meurent; le vent leur nuit; } \\
\text { peuvent boire de l'huile; aiment } \\
\text { le vin, utilisé aussi pour les } \\
\text { guérir; vocifèrent; vivent } 40 \\
\text { ans; n'aiment pas le froid; } \\
\text { aiment les fleuves et y nagent, } \\
\text { pas longtemps à cause de leur } \\
\text { poids; naissent en Inde]. Cf. } \\
\text { VB (reprise) }\end{array}$ & $\begin{array}{l}\text { conservant propter draconem, qui } \\
\text { dum ipsum invenit, subito interficit. } \\
\text { PLINIUS [reprise d'Aristote et autres } \\
\text { sources; mémoire et amour; } \\
\text { pratiques en Inde] Ex libro DE } \\
\text { NATURA RERUM [cf. TC]. Solinus ait } \\
\text { elephantem semel parere, sed revera } \\
\text { ter vel quiquies parit in etate. } \\
\text { 45. De membrorum } \\
\text { c. } \\
\text { elephanticorum creatione } \\
\text { [suite TC, en plus explicite : dents, } \\
\text { langue, trompe, ongles, pieds; } \\
\text { position; doigts; mamelles; intestin; } \\
\text { estomac comme le porc; foie; bile; } \\
\text { sexe; testicules] EX LIBRO DE NATURIS } \\
\text { RERUM [positions, attitudes, pieds, } \\
\text { effraye chevaux et taureaux] } \\
\text { c. 46. De eodem } \\
\text { PLINIUS UBI SUPRA [dos dur, ventre } \\
\text { mou; peu de poils] IDEM IN LIBROXIO } \\
\text { [quatre dents intérieures; peau; } \\
\text { testicules] AMBROSIUS [petit cerveau; } \\
\text { ne plie pas le genou; se frottent sur } \\
\text { les arbres; plus solides que les } \\
\text { hommes] PHYSIOLOGUS } \\
\text { [comportement, petits yeux; peau } \\
\text { dure; Perses l'utilisent dans la } \\
\text { guerre; ventre mou; intérieur comme } \\
\text { le porc, et par conséquent comme } \\
\text { l'homme]. }\end{array}$ \\
\hline
\end{tabular}

\begin{tabular}{|c|c|c|}
\hline $\begin{array}{l}\text { cundum fortit } \\
\text { orporis. Brevia } \\
\text { habet sec }\end{array}$ & $\begin{array}{l}\text {-atine animal } \\
\text { interpretatur, } \\
\text { oc, id est } \\
\text { fevissima } \\
\text { num cornu in } \\
\text { eat quatuor } \\
\text { et validum, ut } \\
\text { lut ventilet aut } \\
\text { oRUS libro } 12 . \\
\text { sepe certamen } \\
\text { tum in ventre } \\
\text { autem est } \\
\text { la venentium } \\
\text { sicut asserunt, } \\
\text { n scripserunt, } \\
\text { sonitur, quae } \\
\text { it, in quo ille }\end{array}$ & 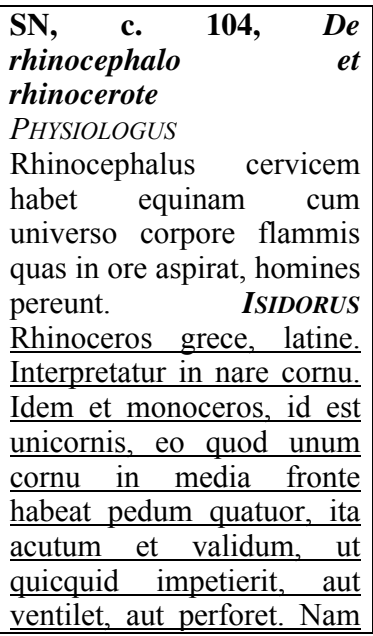 \\
\hline
\end{tabular}




\begin{tabular}{|c|c|c|}
\hline $\begin{array}{l}\text { illo certamen habens in } \\
\text { ventre vulneratum } \\
\text { prosternit. } \\
\text { \$\$ Ut dicit liber } \\
\text { KYRANNIDARUM, cornu } \\
\text { illud demones eicit. } \\
\text { Perforatur enim, et sic } \\
\text { sono et presentia cornu } \\
\text { fugatur demon.\$\$Ferrum } \\
\text { non timet. Manet in } \\
\text { montibus excelsis et in } \\
\text { solitudinibus vastissimis } \\
\text { commoratur. IACOBUS et } \\
\text { YSIDORUS : Sed hoc } \\
\text { argumento capitur: } \\
\text { Puella virgo in silva } \\
\text { proponitur } \\
\text { relinquitur. Qui adveniens } \\
\text { omni ferocitate deposita } \\
\text { casti corporis pudicitiam } \\
\text { in virgine veneratur } \\
\text { caputque suum in sinu } \\
\text { puelle aperientis imponit } \\
\text { Sicque soporatus inermis } \\
\text { deprehenditur } \\
\text { venatoribus, occiditurque } \\
\text { vel in regali palatio ad } \\
\text { spectaculum exhibetur. } \\
\text { Hoc animal primo, ut } \\
\text { PLINIUS dicit, magnus } \\
\text { Pompeius ad spectaculum } \\
\text { Rome exhibuit. Hoc } \\
\text { crudele animal Christum } \\
\text { significat, qui ante } \\
\text { incarnationem seviebat in } \\
\text { celo puniendo angelos } \\
\text { propter superbiam, in } \\
\text { terra homines propter } \\
\text { inobedientiam sicut Adam } \\
\text { et propter luxuriam sicut } \\
\text { Sodomitas, in propter } \\
\text { crapulam sicut filios } \\
\text { Israel. Huic nullo } \\
\text { contradicere audente } \\
\text { clamat YSAIAS: Non est, } \\
\text { inquit, qui consurgat et } \\
\text { teneat te. Hunc virgo in } \\
\text { deserto mundi quasi cepit, } \\
\text { dum gloriose virginis } \\
\text { Marie incomparabili } \\
\text { pulchritudine castitatis } \\
\text { illectus dei filius quasi }\end{array}$ & 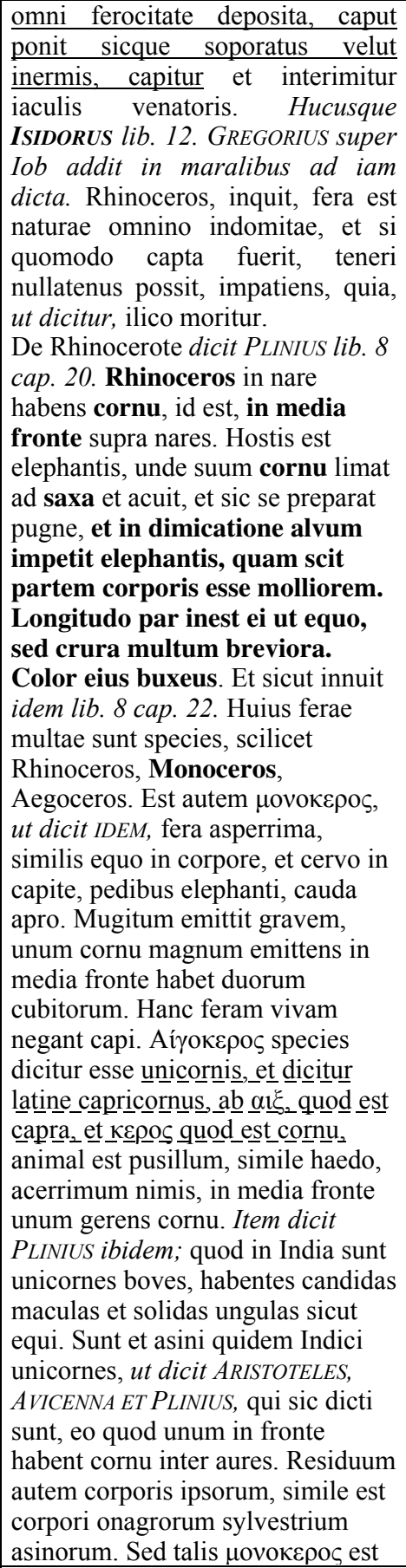 & 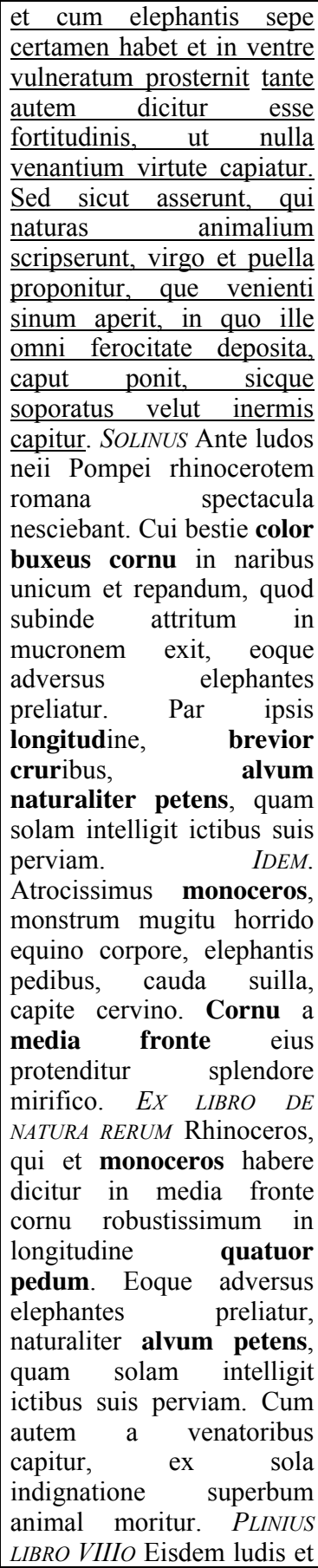 \\
\hline
\end{tabular}




\begin{tabular}{|c|c|c|}
\hline $\begin{array}{l}\text { sinum eius uterum } \\
\text { introivit atque per eam } \\
\text { humanatus corpus accepit, } \\
\text { in quo a Iudeis quasi } \\
\text { crudelissimis venatoribus } \\
\text { comprehensus occiditur, } \\
\text { indeque resurgens et } \\
\text { ascendens ad celos in } \\
\text { celestis regni palatium ad } \\
\text { patris dexteram } \\
\text { collocatur. }\end{array}$ & 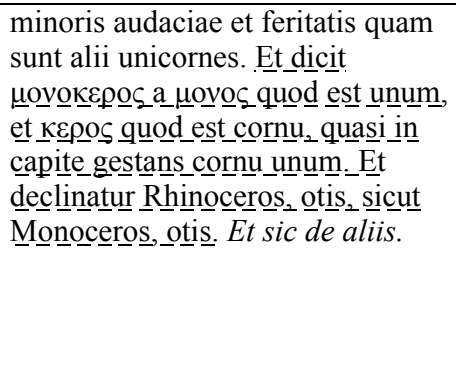 & $\begin{array}{l}\text { rhinoceros unius in nare } \\
\text { cornu qualis sepe visus. } \\
\text { Alter hic genitus hostis } \\
\text { elephanto, cornu ad saxa } \\
\text { limato, preparat se pugne. } \\
\text { In dimicatione alvum } \\
\text { maxime petens, quam scit } \\
\text { esse molliorem longitudo } \\
\text { ei par. Crura multo } \\
\text { breviora, color buxeus. }\end{array}$ \\
\hline
\end{tabular}

Ces exemples le montrent: pour Thomas de Cantimpré et Vincent de Beauvais, il ne subsiste plus de nécessité étymologique; cette méthode d'explication n'agit plus comme une révélation ontologique sur les choses et n'est plus nécessaire à la compréhension du sens. Elle ne détermine plus la connaissance de la chose. Chez Barthélemy l'Anglais, elle demeure cependant assez souvent une porte d'entrée dans la connaissance de la réalité, sans plus être un principe symbolique de l'être, ni le lien, de type platonicien, avec une autre réalité (cf. le début de la notice sur l'éléphant). Ce relatif désintérêt pour la pratique étymologique chez les encyclopédistes est à comprendre comme un abandon de son sens profond.

En revanche, nous avons pu observer que dans le Liber introductorius de Michel Scot à peu près contemporain (Michel Scot est mort en 1237), l'étymologie a gardé toute son importance presque magique, significative, symbolique, au moins pour les données cosmologiques et métaphysiques. Il est probable que le maintien de ce procédé traditionnel soit dû au type d'enseignement grammatical que Michel Scot avait lui-même reçu, et à l'influence qu'aurait joué l'école parisienne de Petit Pont dans son œuvre ${ }^{39}$. Michel Scot, auteur, était aussi traducteur de nombreuses œuvres de l'arabe au latin, et fut utilisé aux deux titres comme source d'information directe par Arnold de Saxe et Barthélemy l'Anglais pour transmettre des citations d'auteurs antiques ou orientaux peu connus. Son attitude traditionnelle dans le domaine étymologique ne contredit donc pas l'actualité de sa documentation.

En somme, en matière d'histoire naturelle, Isidore est considéré comme une lecture indispensable par les trois encyclopédistes examinés : d'une part en simple initiateur, en ouverture d'un chapitre sur une matière (une plante, un animal, une pierre) - ce que fait aussi Michel Scot en matière d'astronomie - et d'autre part comme réservoir de documentation pour de l'information naturelle, à égalité avec d'autres sources citées. Thomas de Cantimpré et Barthélemy concentrent leurs emprunts aux Etymologies dans l'étude de la nature. Dans d'autres domaines où le savoir et l'enseignement n'a pas été renouvelé, Isidore reste une source extensive et essentielle chez Vincent de Beauvais, en particulier pour le langage et la logique.

S'il existe par ailleurs un domaine où le relais d'Isidore est pérenne, c'est celui de la minéralogie. En effet, son information est restée d'actualité en cette

${ }^{39}$ Cf. P. Morpurgo, «Michele Scoto e la circolazione dei manoscritti scientifici in Italia Meridionale : la dipendenza della Scuola Salernitana dalla Scuola Parigina di Petit Pont », Atti del Congresso sulla diffusione delle Scienze Islamiche nel Medioevo Europeo (2-4 ottobre 1984), Roma, 1987, p. 167-191. 
matière jusqu'à l'avènement de la minéralogie moderne, et même le naturaliste dominicain Albert le Grand, qui au milieu du XIII ${ }^{\mathrm{e}}$ siècle renouvelle, mais synthétise aussi, toute la documentation antérieure sur ce champ de savoir, ne manque jamais de citer Isidore s'il n'a pu trouver d'information plus adéquate à propos d'un minéral.

\section{médiévaux}

3. Les Étymologies, une source fondamentale des lapidaires

Entre le livre XVI des Étymologies d'Isidore de Séville au VII ${ }^{\mathrm{e}}$ siècle et le poème didactique De lapidibus de l'évêque de Rennes Marbode au $\mathrm{XI}^{\mathrm{e}}$ siècle $^{40}$, la minéralogie n'a pas connu d'évolution significative en Occident. Isidore de Séville lui-même prenait, dans son De natura rerum et ses Étymologies, le relais de Pline l'Ancien et de son Histoire naturelle, qui, du livre XXXIII au livre XXXVII, traite de deux cents douze pierres différentes, rassemblées à travers de très nombreuses sources. L'enquête sur la nature de Pline régnait en effet en maître sur la science naturelle latine tardo-antique et médiévale et fut la source d'information de référence du naturalisme latin jusqu'à l'époque moderne. Isidore de Séville aurait néanmoins pu connaître un lapidaire influent de la fin de l'Antiquité : la version latine du lapidaire de Damigéron et $\operatorname{Evax}^{41}$, mais on peut déduire de son silence à ce sujet qu'il ne l'avait lu directement, même si de nombreux parallèles existent entre les deux œuvres $^{42}$. C'est la raison pour laquelle l'Histoire naturelle de Pline est restée pour Isidore le texte sur les pierres le plus abondant et le plus accessible.

Il existait pourtant déjà dans l'Antiquité une véritable tradition de compilation de traités minéralogiques ${ }^{43}$. Parmi les plus originaux de ces traités, il faut mentionner, outre celui qui compile l'apport du grec Damigéron et du latin

\footnotetext{
${ }^{40}$ Première édition critique peu fiable par J. M. Riddle, Marbode of Rennes' (1035-1123) De lapidibus, Considered as a Medical Treatise with Text, Commentary and C.W. King's Translation [...], Wiesbaden, 1977 (Sudhoffs Archiv. Beihefte, 20); remplacée par l'édition critique d'après les manuscrits latins de France par M.-E. Herrera, Marbodo de Rennes. Lapidario. Liber lapidum. Edición, traducción y commentario, Paris, Les Belles-Lettres, 2005 (Auteurs latins du Moyen Âge).

${ }^{41}$ Ed. R. Halleux - J. Schamp, Les lapidaires grecs, Paris, 1985 ; l'édition de E. Abel, Orphei Lithica. Accedit Damigeron de Lapidibus, Berlin, 1881 (réimpr. Hildesheim, 1971), peut encore être utile en comparaison. Celle de J. Radcliffe est difficile à trouver : Damigeron, $D e$ virtutibus lapidum. The Virtue of Stones. Attributed to Damigeron. Transl. by P.P. Tahil, Seattle, 1989.

${ }^{42} \mathrm{La}$ tradition des lapidaires et listes de notices minéralogiques a multiplié les reprises d'Isidore, brouillant souvent le message initial de l'œuvre de Damigeron-Evax, déjà assez obscure par mixité d'influences.

${ }^{43}$ Cf. la revue des lapidaires antiques dans l'introduction de R. Halleux - J. Schamp, Les lapidaires grecs, p. XV à XXXIV; J.M. Riddle, «Lithotherapy in the Middle Ages. Lapidaries considered as medical texts ", Pharmacy in History, 12 (1970), p. 39-50 ; K.M. Wirbelauer, Antike lapidarien, Würzburg, 1937, et la notice «Lapidarien » de la Pauly's Realenzyklopädie.
} 
Evax, celui du disciple d'Aristote Théophraste ${ }^{44}$, dont certains éléments sont passés dans la tradition arabe, et celui qui constitue le livre V de la Materia medica du médecin Dioscoride, contemporain de Pline, qui connut de très nombreuses versions et traductions jusqu'au $\mathrm{XI}^{\mathrm{e}}$ siècle ${ }^{45}$. Parmi les traités écrits ou passés en langue arabe, les plus influents sur la tradition occidentale furent les écrits de Qustâ ibn Luqâ (ca. 820-ca. 912) ${ }^{46}$ et ceux du médecin d'origine tunisienne Constantin l'Africain (mort avant 1098), dont le rôle dans la transmission des données de Dioscoride, de Damigeron-Evax, et de Qustâ ibn Luqâ fut probablement déterminant grâce à son activité de traducteur. Constantin traduisit notamment le De gradibus d'Ibn AlJazzâr (mort en 1004) ${ }^{47}$, qui contient des notices minéralogiques inspirées des traités d'Aristote, de Théophraste et de Dioscoride.

Comme déjà le livre XXXVII de l'Historia naturalis de Pline, les Collectanea rerum memorabilium de Solin ou les Étymologies d'Isidore, tous ces traités témoignent de l'usage, d'origine proche-orientale, de porter des pierres en amulette. Cet usage avait gagné l'Empire romain, dont émanent plusieurs œuvres d'époque tardive consacrées aux pierres, comme celle de Damigéron. La tradition littéraire a dès lors conservé - et parfois ajouté - des éléments sur les propriétés magiques des pierres.

$\mathrm{Au}$ Moyen Âge, cette littérature spécialisée a connu un nouveau développement, où les deux auteurs-relais les plus importants et les plus innovants furent au $\mathrm{XI}^{\mathrm{e}}$ siècle l'évêque Marbode de Rennes et au milieu du XIII ${ }^{\mathrm{e}}$ siècle le dominicain Albert le Grand. Le premier écrivit un poème sur les pierres précieuses qui synthétise à la fois la tradition chrétienne médiévale et la tradition profane antique (principalement à travers l'Historia naturalis, le traité de Damigéron-Evax et les Etymologies), tandis que le second traite de tous les minéraux dans son $D e$ mineralibus $^{48}$, un commentaire philosophique - on dirait aujourd'hui scientifique -

\footnotetext{
${ }^{44}$ E.R. Caley - J.F.C. Richard, Theophrastus on Stones. Introduction. Greek Text. English Translation and Commentary, Columbus, Ohio, 1956; D.E. Eichholz, Theophrastus de Lapidibus, Oxford, 1965.

${ }^{45}$ Sur Dioscoride, voir entre autres le Dictionary of Scientific Biography, s.v. « Dioscorides ». Sur la transmission médiévale de Dioscoride, J.M. Riddle, "Dioskorides», Catalogus Translationum et Commentariorum, t. 4, Washington, 1981, p. 1-143 ; Id., " Dioskurides im Mittelalter : Überlieferung », Lexikon des Mittelalters, t. 3, col. 1095-1097 ; Id., Dioscorides on Pharmacy and Medicine, Austin, 1985; Id., "The Latin Alphabetical Dioscorides Manuscript Group ", Proceedings of the XIIIth International Congress for the History of Science, Acts Section IV, Moscou, 1971.

${ }^{46}$ Cf. G. Gabrieli, « Nota biobibliographica su Qustâ ibn Lûqâ », Rendiconti della Accademia dei Lincei. Classe di scienze morali, storiche e filologiche, $5^{\text {th }}$ ser. 21 (1912), p. 341-82; J. Wilcox, «Our Continuing Discovery of the Greek Science of the Arabs: The Example of Qustâ ibn Lûqâ », Annals of Scholarship, 4 (n³, 1987), p. 57-74 ; et E.R. Harvey, art. s.v. dans Dictionary of Scientific Biography, New York, 1975, p. 244-246.

${ }^{47}$ Édition : Constantini Africani Opera Omnia, t. 2, Basel, 1539, p. 342-387.

${ }^{48}$ L'édition la plus accessible est celle publiée par A. Borgnet en 1890 dans les Opera omnia d'Albert le Grand, mais elle présente de très nombreux défauts et une normalisation des noms de pierres qui éloigne du témoignage des manuscrits médiévaux. Il est donc utile de se référer aussi à l'édition de 1517 à Oppenheim.
} 
qui ajoute à la tradition antique et médiévale l'acquis des traductions arabo-latines et de ce qu'il a pu recueillir de l'apport d'Aristote dans le domaine minéralogique ${ }^{49}$. Chez ces deux spécialistes illustres, les informations sur les pierres tirées directement, ou via des sources secondaires, des Étymologies, restent largement présentes, à l'instar de l'influence que l'œuvre a exercée depuis sa rédaction, jusqu'à son déclin au cours du XIII ${ }^{\mathrm{e}}$ siècle.

Ces deux œuvres sont, chacune à leur manière, des modèles du genre des « lapidaires scientifiques », que nous privilégions dans cette contribution. Il ne sera en revanche pas question de la veine des lapidaires chrétiens. Ces derniers se fondent sur les pierres présentes dans la Bible et plus précisément sur le pectoral porté par le grand prêtre Aaron; ils visent à donner des pierres une explication symbolique ou allégorique. C'est le cas, par exemple, des portions minéralogiques des différentes versions du Physiologus ou des bestiaires latins et vernaculaires qui s'en inspirèrent, mais aussi des différentes versions du Lapidaire chrétien ${ }^{50}$. Les lapidaires qu'on peut qualifier de «scientifiques» cherchent quant à eux à apporter une information rationnelle et utilitaire sur les corps minéraux, grâce à des éléments descriptifs concernant la couleur, la forme, la ressemblance avec d'autres pierres, et l'emploi thérapeutique ou artistique potentiel du minéral. Ils puisent leur documentation dans les lapidaires antérieurs, parmi lesquels la documentation de Pline et d'Isidore tiennent une place de relais considérable.

\subsection{CATALOGUES DE PIERRES : LES EMPRUNTS CUMULES DE LA TRADITION ENCYCLOPEDIQUE AUX ETYMOLOGIAE}

Ci-dessous, un tableau des pierres représentées chez les lapidaristes antiques et médiévaux les plus féconds permet d'un coup d'oeil de juger des emprunts d'information chez les différents lapidaristes et de comparer leur apport avec les données propres à Isidore.

Dans les Étymologies, la matière minéralogique, qui se diversifie sous le nom de soixante-dix substances différentes, se présente de la manière suivante. Après avoir traité des sables, des poudres et de la glaise sur terre et dans l'eau, puis des pierres communes et des marbres, Isidore classe les pierres précieuses d'après leur couleur unique ou leur association de coloris, une distinction que ne font plus les lapidaristes postérieurs. En effet, à partir du XIII ${ }^{\mathrm{e}}$ siècle, la commodité de l'ordre

\footnotetext{
${ }^{49}$ On se reportera, pour un panorama plus général de l'évolution de la minéralogie dans les encyclopédies, à la contribution suivante: I. Draelants, «La science encyclopédique des pierres au XIII' siècle : l'apogée d'une veine minéralogique », Aux origines de la géologie de l'Antiquité à l'âge classique. Actes du Colloque de la Sorbonne, 10-12 mars 2005, éd. Cl. Thomasset, J. Ducos, J.-P. Chambon, Paris, 2008, [40 p.].

${ }^{50}$ Cf. L. Baisier, The Lapidaire chrétien, Its Composition, Its Influence, Its Sources, Washington, 1936 (thèse de doctorat publiée de la Catholic Univ. of America). Ce travail, valable pour le lapidaire chrétien, n'a pas approfondi les autres lapidaires qui furent diffusés au Moyen Âge et tire souvent des conclusions fautives à partir d'éléments issus de ces autres sources chez les auteurs médiévaux. Voir surtout Chr. Meier, Gemma spiritalis. Methode und Gebrauch der Edelsteinallegorese vom frühen Christentum bis ins 18. Jahrhundert, t. 1, München, 1977.
} 
alphabétique prend le dessus sur tout autre classification. Viennent ensuite chez Isidore les cristaux (toujours parmi les pierres précieuses), les pierres ignées ou enflammables, et les pierres dorées. Suivent les métaux, puis un chapitre $(25, D e$ ponderibus) sur les unités de mesure, qui clôt le livre XVI. Cette section est totalement abandonnée lors de la postérité encyclopédique d'Isidore, puisque ces mesures antiques n'avaient plus de sens au Moyen Âge. À l'intérieur de ce classement général, Isidore applique diverses règles de classification. Fidèle au critère onomastique, il range les noms de pierre en fonction de leur homonymie partielle. Par exemple, cynophtalmus précède lycophtalmus, synocitide précède ananchitide, et la plupart des pierres commençant par chryso- sont rangées à la suite. Intervient également un critère logique de classement. Par exemple, les pierres qui sont présentes dans les corps des animaux sont présentées à la suite, comme chelonites (hirondelles), brontia (tortue), hyaenia (hyènes).

Voici les œuvres figurant dans le tableau ci-dessous ${ }^{51}$ : col. 1 : Étymologies d'Isidore; col. 2: Marbode de Rennes, Liber lapidum; col. 3: Solin, De rerum memorabilium ; col. 4 : Damigéron-Evax (en latin); col. 5, Dioscoride Lombard ${ }^{52}$; col. 6, Constantin l'Africain, De gradibus ; col. 7, Qustâ ibn Lûqâ, De physicis ligaturis $^{53}$; col. 8, De proprietatibus rerum de Barthélemy l'Anglais, col. 9, Liber de natura rerum, de Thomas de Cantimpré, col. 10: Arnold de Saxe, De floribus rerum naturalium III, I, De natura lapidum et IV, 8 ; col. 11 : De mineralibus d'Albert le

\footnotetext{
${ }^{51}$ Une version moins détaillée de ce tableau, limitée aux auteurs du XIIIe siècle et aux pierres considérées comme précieuses, a été publiée en annexe de l'article suivant : I. Draelants, « La science encyclopédique des pierres au XIII ${ }^{\mathrm{e}}$ siècle... », (op. cit.).

${ }^{52}$ Ed. K. Hoffmann - T.M. Auracher, «Der Longobardische Dioskorides des Marcellus Virgilius », Romantische Forschungen, 1 [1882], p. 49-105, 10 [1897], p. 181-247 et p. 369446 ; 11 [1899], p. 1-121; 13 [1902], p. 161-243; 14 [1903], p. 601-37. Édition continuée par H. Stadler, «Dioscorides Langobardus (cod. Lat. Monac. 337) », Romanische Forschungen, 13 (1902), p. 161-243; 14 (1903), p. 601-36.

53 Édition J. Wilcox - J.M. Riddle, "Qustâ ibn Lûqâ's Physical Ligatures and the Recognition of the Placebo Effect», Medieval Encounters. Jewish, Christian and Muslim Cultures in Confluence and Dialogue, 1 (1995), p. 1-50 (texte p. 31-39).
} 
Grand $^{54}$; col. 12 : livres VI-VIII du Speculum naturale de Vincent de Beauvais. La croix indique que le nom de la pierre chez Isidore est conservé tel quel par ses successeurs.

Nous ne faisons pas figurer dans le tableau les métaux et minéraux suivants représentés dans les Étymologies, car ils interviennent le plus souvent chez les différents auteurs dans des chapitres distincts des catalogues lapidaires: aes, cyprium, argentum, aurichalcum, aurum, obryzum, cadmia, electrum, ferrum, plumbum, scoria, stannum.

${ }^{54}$ Pour Albert le Grand, en cas de différence avec le nom de la pierre chez Isidore, nous avons retenu la leçon de l'édition d'Oppenheim, 1517, généralement plus fiable, plutôt que celle rétablie par A. Borgnet en 1890. 


\begin{tabular}{|c|c|c|c|c|c|c|c|c|c|c|c|}
\hline Isidore & Marb. & $\begin{array}{c}\text { Sol } \\
\text { in }\end{array}$ & Dam.-Evax & Diosc. & $\begin{array}{l}\mathrm{De} \\
g r .\end{array}$ & $\begin{array}{l}\text { Phys } \\
\text {. lig. }\end{array}$ & Barthélemy l'A. & $\begin{array}{l}\text { Thomas de } \\
\text { Cantimpré }\end{array}$ & $\begin{array}{l}\text { DFRN III, I } \\
\text { (et IV) }\end{array}$ & $\begin{array}{c}\text { Albert le } \\
\text { Grand }\end{array}$ & $\begin{array}{l}\text { Vincent de } \\
\text { Beauvais }^{1}\end{array}$ \\
\hline 1 & & & arnosteatites & & & & & & & & \\
\hline $\begin{array}{l}\text { Asbestos } \\
\text { Amiantos } \\
\text { Ostracites }\end{array}$ & abeston 33 & & & $\begin{array}{l}\mathrm{x} \\
\mathrm{x}\end{array}$ & & & $\mathrm{x} 12$ & $\begin{array}{l}\text { abeston } 5 / / 5 \\
\text { amandinus } / / 10 \\
\text { amanthes } 6 \\
\text { amiantos } 6 / / \\
\end{array}$ & $\begin{array}{l}\text { abeston } 1 \\
\text { amandinus } 7\end{array}$ & $\begin{array}{l}\text { abeston } 1 \\
\text { amandinus } 7\end{array}$ & $\begin{array}{l}\text { x } 27^{2}(\mathbf{1 0 6}) \\
{ }^{3} \text { amanthus } 27(\mathbf{1 0 6})\end{array}$ \\
\hline Apsyctos & absictos 52 & & & & & & & absintus $8 / / 8$ & abscintus 2 & absinthus 3 & x 36 (109) \\
\hline Adamas & $\mathrm{x} 1$ & & $\mathrm{x}$ & & & $\mathrm{x}$ & $\times 99$ & $\mathrm{x} 4 / / 4$ & x 3 (+IV) & $\times 2$ & X 39 (109), 40,41 \\
\hline Achates & $\times 2$ & $\mathrm{x}$ & $\mathrm{x}$ & & & & $\mathrm{x} 11$ & $\mathrm{x} 3 \mathrm{XII} / / 3$ & $\mathrm{x} 4$ & agathes 4 & x 37 (109), 38 \\
\hline 1 & & & adamicos & & & & & & & & \\
\hline Aegyptilla & & & $\mathrm{x}$ & & & & & & & & ${ }^{4} \times 30,66$ \\
\hline Agapis & & & & $\mathrm{x}$ & & & & & & & x 42 (110) \\
\hline Alabandina & alabanda 21 & & & & & & x 14 & $\begin{array}{l}\times 9 / / \\
\text { alabandia } 9\end{array}$ & $\begin{array}{ll}\begin{array}{l}\text { alabandyma } \\
(+\mathrm{IV})\end{array} & 5 \\
\end{array}$ & $\mathrm{x} 5$ & $\begin{array}{l}\text { x } 42 \\
\text { alabandicus } 16 \text { (102) }\end{array}$ \\
\hline Alabastrites & 1 & & & & & & & //nychomar & $\begin{array}{|ll|}\text { Nicomar } & 58\end{array}$ & ${ }^{5}$ nicomar 66 & nicomar $^{6}$ \\
\hline
\end{tabular}

${ }^{1}$ En gras et entre parenthèses, les notices déjà représentées sous ce nom dans la version bifaria du Speculum naturale.

${ }^{2}$ Cette pierre figure dans un chapitre précède la liste alphabétique du livre VIII.

${ }^{3}$ Sous ce nom, Vincent de Beauvais s'inspire de Pline dans une notice qui précède le catalogue alphabétique des pierres. Il ne fait pas de rapport avec l'amandinus

qu'on trouve chez Arnold de Saxe ou l'amiantos de Thomas de Cantimpré, notices qu'il ne recopie pas.

${ }^{4}$ Repris, sous le nom d'Isidore, dans la liste des pierres de couleur noire. 


\begin{tabular}{|c|c|c|c|c|c|c|c|c|c|}
\hline (marmor) & & & & $\mathrm{x}$ & alabastrites 3 & $=$ alabastrum 56 & $=$ alabasteum & $=$ alabastrum & alabastrites 16 (102) \\
\hline $\begin{array}{l}\text { Alectria } \\
\text { alectoria }\end{array}$ & allectorius 3 & $\mathrm{x}$ & alectorius & $\mathrm{x}$ & $\begin{array}{l}\text { x } 17 \\
=\text { alectorius }\end{array}$ & allectorius $7 / / 7$ & alectorius 6 & alecterius 6 & alectorius 43 (110) \\
\hline 1 & & & alcinio & & & & & & \\
\hline $\begin{array}{l}\text { Amethystus } \\
\text { Amethystizon }\end{array}$ & $\mathrm{x} 16$ & & & & $\mathrm{x} 10$ & $\mathrm{x} 2 \mathrm{XII} / 2$ & $\begin{array}{l}\text { amatistus } \\
(+\mathrm{IV})\end{array}$ & $\mathrm{x} 8$ & x 44 (110) \\
\hline Ammochrysus & & & & & & & & & aramochrysus 30 \\
\hline Androdamas & androdragma 48 & $\mathrm{x}$ & & & & andromanda $10 / / 11$ & androdamanta 9 & andromanta 9 & $\begin{array}{l}\text { androdamantus } 28 \\
\text { (106) / } \\
\text { androdamanta } 45\end{array}$ \\
\hline Ananchitides & & & & & & & & & ${ }^{7} \times 32$ \\
\hline Apsyctos & & & & & & & 1 & 1 & absyctos 36 \\
\hline 1 & & & anthropocrinus & & & & & & \\
\hline Arabicus & & & & & 1 & 1 & 1 & 1 & ${ }^{8}$ arabus 28 \\
\hline Argyrites & & & & & 1 & 1 & 1 & 1 & 1 \\
\hline Aromatites & & & & & & & & & ${ }^{9} \mathrm{x} 30$ \\
\hline
\end{tabular}

${ }^{5}$ Albert pourrait avoir emprunté à Isidore la propriété de frâicheur. En effet, Et expertum est de hoc, quod frigiditate sua conservat aromatica unguenta correspond aux Étymologies, XVI, 5.

${ }^{6}$ Dans la liste des chapitres, mais la notice manque.

${ }^{7}$ Sous le nom d'Isidore dans un chapitre sur les dénominations et les effets.

${ }^{8}$ Vincent de Beauvais dit la même chose qu'Isidore, mais sa source est Pline. 
Isabelle DRAELANTS

\begin{tabular}{|c|c|c|c|c|c|c|c|c|c|c|c|}
\hline Asius & & & & & & & & & & x 46 (110) & \\
\hline Asterites & & & & & & & & 1 & 1 & $\times 30,46$ & \\
\hline Astrios & & & & & & & & 1 & 1 & $\mathrm{x} 46$ & \\
\hline & & & & $\mathrm{x}$ & & $\begin{array}{l}\text { balagius } \\
=\text { carbunculus } 26\end{array}$ & $\begin{array}{l}\text { cf. carbunculus } 26 \\
\text { (balaustus) }\end{array}$ & \begin{tabular}{|l|} 
balagius $\quad 10 \quad /$ \\
carbunculus
\end{tabular} & $\begin{array}{l}\text { balagius } 10 \\
=\text { palatius } \\
=\text { carbunculus }\end{array}$ & balamites 47 & \\
\hline Balanitae & & & & & & & & 1 & 1 & 1 & \\
\hline Baroptis & & & & & & & & 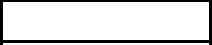 & 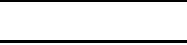 & $\mathrm{x} 30$ & \\
\hline Belioculus & & & & & & 1 & 1 & 1 & 1 & 1 & \\
\hline $\begin{array}{l}\text { Berillus } \\
\text { Chrysoberillus }\end{array}$ & $\mathrm{x} 12$ & $\mathrm{x}$ & $\mathrm{x}$ & & & $x 21$ & $\mathrm{x} 11 \mathrm{XII} / / 12$ & x 11 (+IV) & $\mathrm{x} 12$ & x 47-48 (111) & \\
\hline $\begin{array}{l}\text { Bitumen, } \\
\text { Alumen, } \\
\text { Sal, } \\
\text { Nitrum, } \\
\text { Chalcantum }^{10}\end{array}$ & & & & & $\mathrm{x}$ & & & & & $\begin{array}{l}x \mathrm{~V}, 92 \\
\mathrm{x} V, 94 \\
x, V, 82-89\end{array}$ & \\
\hline Brontia & & & & & & & & 1 & 1 & bronia 32 & \\
\hline 1 & & capnites & & & & & & & & & \\
\hline Carchedonia & × 6 & chalcedonius & & & & chalcedonius 28 & calcedonius $14 / / 15$ & calcidonius 12 & calcidonius 14 & chalcedonius & 50 \\
\hline
\end{tabular}

${ }^{9}$ Dans une liste des genres et couleurs de pierres, sans consacrer de notice particulière à cette pierre. De même pour asterites, baroptis, choaspites, chrysocolla chrysopis, chrysolampis, cyanea, mesomelas, pontica, etc.

${ }^{10}$ Classés chez Isidore dans les Gleba ex aqua. Le nitre reçoit une notice indépendante chez presque tous les encyclopédistes. 


\begin{tabular}{|c|c|c|c|c|c|c|c|c|c|c|}
\hline & & & & & & & & & & (111) \\
\hline Carbunculus & $x 23$ & & & & $\mathrm{x}$ & $\begin{array}{l}\text { x } 26 \\
=\text { antrax, balagius }\end{array}$ & $\begin{array}{l}\mathrm{x} 13 \mathrm{XII} / 14 \\
=\quad \text { antrax, rubith, } \\
\text { balaustus }\end{array}$ & $\begin{array}{l}x \quad 13 \quad(+I V) \\
=\operatorname{antrax}\end{array}$ & $\begin{array}{l}\mathrm{x} 13 \\
=\quad \text { anthrax } \\
\text { (balagius, } \\
\text { granatus, } \\
\text { rubinum } \\
\text { granatus 46) } \\
\end{array}$ & $\begin{array}{l}\mathrm{x} 51,52 \\
=\text { antrax } \\
\text { antracites } 45(\mathbf{1 1 0}) \\
\text { rubith } 51\end{array}$ \\
\hline $\begin{array}{l}\text { Chalazia I } \\
\text { Chalazias }\end{array}$ & gelacia 37 & & & & & chalazia 51 & gelasia 33//41 & galacia 40 & gelosia 42 & $\begin{array}{l}\text { gelatia / galatias } 74 \\
\text { (galacies 116) }\end{array}$ \\
\hline Chalcites & & & & & & & & 1 & 1 & $\times 32$ \\
\hline Chalcophonos & $\begin{array}{l}\text { chalcophanos } \\
53\end{array}$ & $\mathrm{x}$ & & & & chalcophonus 59 & $\begin{array}{l}\text { calcophanus } \quad 18 / / \\
\text { calophagus } \\
=\text { calcophonos } 19 \\
\end{array}$ & calcofanes 14 & calcaphanos 15 & chalcophanus 50 \\
\hline Carcinias & & & & & & & & 1 & 1 & ${ }^{11}$ caccine 32 \\
\hline Chelidonia & $\mathrm{x} 17$ & & chelidonius & $\mathrm{x}$ & & x 30 & celidonius 17//18 & celydonius 16 & celidonius 17 & $\begin{array}{l}\text { x } 53(\mathbf{1 1 2}) \\
\text { chelidonius }\end{array}$ \\
\hline Chelonites & x 39 & & $\mathrm{x}$ & & & & //celonites 25 & celonites 17 & celonites 18 & chelonites 54 \\
\hline $\begin{array}{l}\text { Iudaicus } \\
/\end{array}$ & cegolitus 55 & ${ }^{12} \mathrm{x}$ & & iudaicus & & & $\begin{array}{l}\text { iudaicus } 39 \\
\text { gecolitus } 34 / / 42 \\
/ / \text { cegolitus } 26\end{array}$ & cegolitus 18 & \begin{tabular}{|l|} 
iudaicus 51 \\
cegolites 19 \\
${ }^{13}$ gecolitus 44
\end{tabular} & $\begin{array}{l}\text { iudaicus } 5(\mathbf{1 0 1}) \\
{ }^{14} \text { teogolithus } \\
106(\mathbf{1 2 3})\end{array}$ \\
\hline
\end{tabular}

${ }^{11}$ Dans un chapitre général sur les dénominations des pierres, fondée sur leur origine et leur nom, comme bronia, chalcites et carcinias.

${ }^{12}$ tecolithos.

${ }^{13}$ Les termes sont identiques à Isidore, mais c'est Pline que Vincent de Beauvais cite. 
Isabelle DRAELANTS

\begin{tabular}{|c|c|c|c|c|c|c|c|c|c|c|}
\hline Ceraunium & $\mathrm{x} 28$ & & $\mathrm{x}$ & & & ceraunia 32 & ceraunius $21 / / 22$ & $\mathrm{x} 15$ & ceraurus 16 & ceraunius 55 (112) \\
\hline Choaspites & 1 & & & & & & & 1 & 1 & x 30 \\
\hline $\begin{array}{l}\text { Chernites } \\
\text { Ostracites } \\
\text { (ebur) }\end{array}$ & I & & & & & & & & & $\begin{array}{l}\text { chemites } 26 \\
\text { x } 89\end{array}$ \\
\hline Chrysites & 1 & & & & & 1 & 1 & 1 & 1 & 1 \\
\hline Corallium & $\mathrm{x} 20$ & $\mathrm{x}$ & $\mathrm{x}$ & $\mathrm{x}$ & $\mathrm{x}$ & x 33 & corallus $15 / / 16$ & 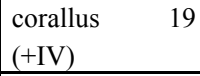 & corallus 20 & coralius 56,57 (112) \\
\hline Coranus & 1 & 1 & & & & 1 & 1 & 1 & 1 & 1 \\
\hline / & corneolus 22 & / & 1 & & $\mathrm{x}$ & corneolus 34 & coreneolus $22 / / 23$ & corneolus 20 & corneolus 21 & $\begin{array}{l}\text { cornelius } \\
=\text { corneolus } 58\end{array}$ \\
\hline Chrysocolla & & & & & & & & 1 & & $\mathrm{x} 30$ \\
\hline Chrysoprasius & x 14 & $\mathrm{x}$ & & & & chrysoprasus 27 & crisprassus $16 / /$ & crisoprassus 21 & crisopassus 22 & $\begin{array}{ll}\text { chrysoprasius } & 61 \\
\text { (113) } & \\
\end{array}$ \\
\hline Chrysopasus & crisopatius 60 & $\mathrm{x}$ & & & & & crisopassus 17 & & & chrysoprasius 62 \\
\hline Chrysopis & & & & & & & & & & $\times 30,59$ \\
\hline Chrysotythus & & & & & & & & & & ${ }^{15}$ crysolithus 60 \\
\hline Crisolitus & $\mathrm{x} 11$ & & $\begin{array}{l}\mathrm{x} \\
\text { chrysolitus alter }\end{array}$ & & & chrysolithus 29 & $\begin{array}{l}\text { crisoletus 20// } \\
\text { crisolectrus } 21\end{array}$ & crisolitus 22 & crisolirus $23^{16}$ & chrysolithus 60 (113) \\
\hline & {$[\mathrm{cf}$.} & & & & & & & filaterium 37 & filecterium 39 & filaterus 72 \\
\hline
\end{tabular}

${ }^{14}$ Source : Solin. Pas d'emprunt à Thomas de Cantimpré et à Arnold de Saxe.

${ }^{15}$ La notice de l'édition de Douai mêle différentes pierres désignées par des noms différents chez Isidore de Séville.

${ }^{16}$ Graphie de l'édition d'Oppenheim, 1517, du De mineralibus. Ed. A. Borgnet, 1890 : chrysolitus. 


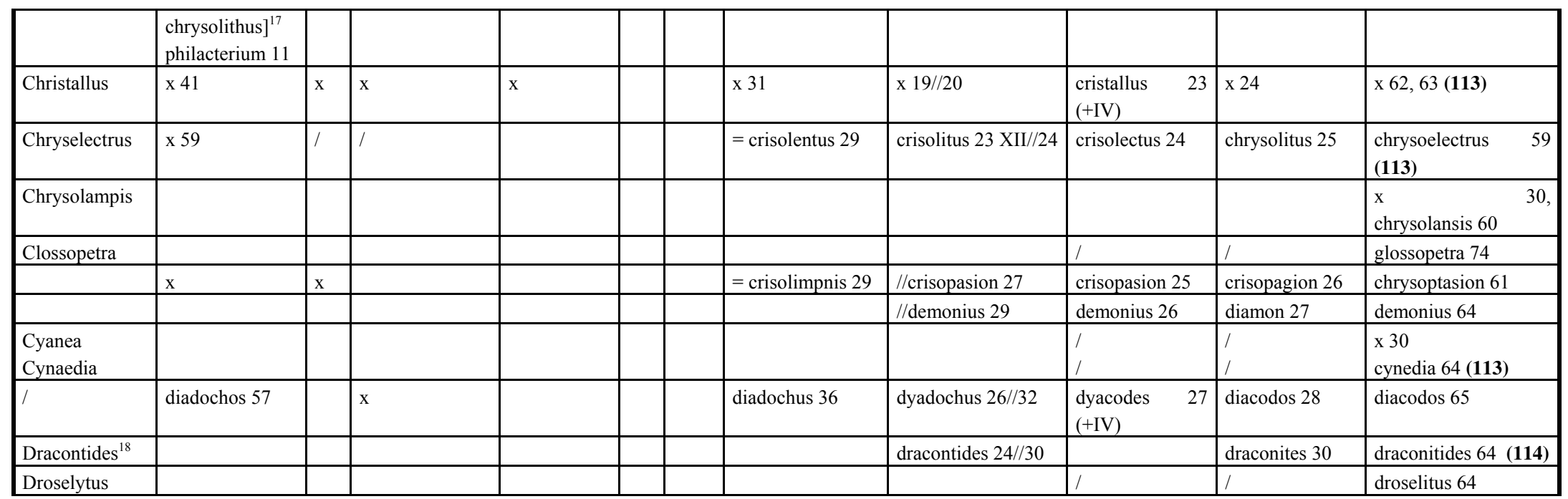

${ }^{17}$ Il s'agit du «philactère », c'est-à-dire d'un talisman protecteur.

${ }^{18}$ Il y a peut-être emprunt à Pline, Historia naturalis, XXXVII, 158, qui reprend les dires de Sotacos, lapidariste du III ${ }^{\mathrm{e}}$ siècle. La dracontia ou dracontitis est extraite du crâne d'un serpent durant son sommeil. De naturis rerum, XIV, 24: Dracontides lapis est, qui ex cerebro draconis trahitur. Qui nisi viventi draconi excisus fuerit, non fit gemma. Quod fit hoc modo : audaces viri explorant draconis specus et dormientium draconum capita subito transverberant, sicque in pleno vigore palpitantibus gemmas extrahunt. ( $2^{\mathrm{e}}$ version ajoute :) Valere dicitur contra venenata animalia et resistere veninis efficaciter. Horum insignibus orientales reges maxime gloriantur. Sunt autem quidam coloris translucidi. 


\begin{tabular}{|c|c|c|c|c|c|c|c|c|c|}
\hline Dyonisias & dionisia 58 & $\mathrm{x}$ & & & dionysias 35 & dyonisia $25 / 31$ & $\begin{array}{l}\begin{array}{l}\text { dyonisia } \\
(+\mathrm{IV})\end{array} \\
\end{array}$ & dyonysia 29 & dionysia 65 (114) \\
\hline $\begin{array}{l}\text { Electrum } \\
\text { succinus }\end{array}$ & & $\begin{array}{l}\text { suc } \\
\text { cin } \\
\text { us }\end{array}$ & & & electrum 38 & $\begin{array}{l}\text { electon / } \\
\text { succinus 54//78 }\end{array}$ & & $\begin{array}{l}x \\
=x 90\end{array}$ & $\begin{array}{l}\text { succinus/electron } \\
103 \mathbf{( 1 2 2 )}, 104,105\end{array}$ \\
\hline 1 & & & diphyes & & & & & & \\
\hline Epimelas & & & & & & & & & $\times 30$ \\
\hline $\begin{array}{l}\text { Aethitae } \\
\text { Aethites } \\
\text { Echites }\end{array}$ & echites 25 & & $\mathrm{x}$ & $\mathrm{x}$ & etites 39 & ethites $28 / 34$ & ethytes 29 & echites 31 & ethites 23 (106), 71 \\
\hline Aegophtalmos & & & $\mathrm{x}$ & & & & 1 & 1 & egophthalinus 32 \\
\hline Aethiopicus & & & & & & & 1 & 1 & etiopicus 32 \\
\hline Heliotropium & eliotropia 29 & & $\mathrm{x}$ & & $\mathrm{x} 41$ & elitropia 29 & 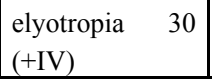 & eliotropia 5 & x 67 (114) \\
\hline Haematites & $\mathrm{x}$ & & $\mathrm{x}$ & $\mathrm{x}$ & hematites 40 & emathites $27 / 33$ & emathytes 31 & ematites 33 & $\begin{array}{l}\text { emathites } 68 \text { (115), } \\
69\end{array}$ \\
\hline $\begin{array}{l}\text { Enhydius } \\
\text { enhydros }\end{array}$ & enidrus 46 & $\mathrm{x}$ & & & enhydros 42 & $\begin{array}{l}\text { eligros } 30 \\
=\text { enydros } 38\end{array}$ & enydros 32 & etindros 35 & enydros 70 (115) \\
\hline \multicolumn{10}{|l|}{ Ephesius } \\
\hline $\begin{array}{l}\text { Hephaestites } \\
\text { Hephaestistes }\end{array}$ & epistites 31 & & $\mathrm{x}$ & $\mathrm{x}$ & epistides 43 & //episcutes 36 & epystrites 33 & epistrides 34 & epistrites 70 \\
\hline $\begin{array}{l}\text { Hexecontalithu } \\
\text { s }\end{array}$ & exacontalitus 38 & & & & exolicetus 44 & & exacontalitus 35 & exacontalitus 37 & $\begin{array}{ll}\text { exacontalitus } & 71 \\
\text { (115) } & \end{array}$ \\
\hline & $\mathrm{x}$ & & & & & //exacolitus 37 & exacolitus 34 & exacolitus 36 & \\
\hline
\end{tabular}




\begin{tabular}{|c|c|c|c|c|c|c|c|c|c|c|c|}
\hline 1 & & & epignathion & & & & & & & & \\
\hline Exhebenus & & $\mathrm{x}$ & $\mathrm{x}$ & $\mathrm{x}$ & & & & & & 1 & ebenus $66(\mathbf{1 1 4})$ \\
\hline & & & & $\begin{array}{l}\text { auripig- } \\
\text { mentum }\end{array}$ & $\mathrm{x}$ & & auripigmentus 6 & & $\begin{array}{l}\text { falcanos } \\
{[=\text { arsenicum }]}\end{array}$ & $\begin{array}{l}\text { falcones } 38 \\
=\text { arsenicum } \\
= \\
\text { auripigmentum }\end{array}$ & $\begin{array}{l}\text { falcanos } 72 \\
=\text { asenicum } \\
=\text { auripigmentum }\end{array}$ \\
\hline Gagates & $\mathrm{x} 18$ & $\mathrm{x}$ & $\mathrm{x}$ & $\mathrm{x}$ & & & x 32//40 & $\mathrm{x}$ & gagates 38 & $\begin{array}{l}\text { x } 40 \\
=\text { kacabre }\end{array}$ & x 22 (105) \\
\hline & & & & $x$ & $\mathrm{x}$ & & chabrates 58 & (v. gagates) & $\begin{array}{l}\begin{array}{l}\text { kacabre } \\
\text { =gagates }\end{array} \\
\end{array}$ & $\begin{array}{l}\text { kacabre } 53 \\
=\text { gagates }\end{array}$ & kacabre 78 \\
\hline & & & & & & & [v. chabrates] & & kabrates 49 & kabrates 54 & kabrates 78 \\
\hline I & $\begin{array}{l}\text { gagatromeum } \\
27\end{array}$ & 1 & gagatromeos & & & & & $\begin{array}{l}\text { gagatromeus } 36 \\
\text { //44 }\end{array}$ & gagatromeo 39 & gagatronica 41 & 1 \\
\hline $\begin{array}{l}\text { Gallactites } \\
\text { Galactites }\end{array}$ & galactida 42 & & $\mathrm{x}$ & $x$ & & & $\mathrm{x} 50$ & galaritides $35 / / 43$ & galactydes 41 & $\begin{array}{l}\text { galaricides } 43 \\
=\text { galarictides }\end{array}$ & X 73 (116) \\
\hline / & gerachites 30 & I & hieracites & & & & $\begin{array}{l}\text { geranites } 52 \\
=\text { hieracites } 102\end{array}$ & //gerachirea 45 & gerachitem 42 & gerachidem 45 & hieracites 75 \\
\hline Gypsum & & & & & & & & & 1 & & $\mathrm{x} 11$ \\
\hline Hormesion & & & & & & & & & 1 & 1 & ermistio 71 \\
\hline Iaspis & $\mathrm{x} 4$ & $\mathrm{x}$ & $\mathrm{x}$ & $\mathrm{x}$ & & & $\mathrm{x} 53$ & x 37 XII //46 & $\mathrm{x} 43$ & $\mathrm{x} 52$ & x 77 (117) \\
\hline $\begin{array}{l}\text { Hyacinthus } \\
\text { Hyacinthizon }\end{array}$ & iacincthus 15 & & & & $\mathrm{x}$ & $\mathrm{x}$ & $\begin{array}{l}\text { hyacinthus } \\
\text { granatus, citrinus, } \\
\text { venetus, } 54\end{array}$ & \begin{tabular}{|l|} 
granatus $31 / / 39$ \\
iacinctus $38 \quad \mathrm{XII} /$ \\
47
\end{tabular} & $\begin{array}{l}\text { iacintus } \\
\text { aquaticus } 44\end{array}$ & $\begin{array}{l}\text { hyacinthus } \\
\text { aquaticus } 48\end{array}$ & $\begin{array}{l}\text { hyacinthus granatus, } \\
\text { citrinus, venetus } 76 \\
\text { (117) }\end{array}$ \\
\hline [v. saphirus] & $\mathrm{x}$ & & & & & & & & Iacintus & hyacinthus & \\
\hline
\end{tabular}




\begin{tabular}{|c|c|c|c|c|c|c|c|c|c|c|}
\hline & & & & & & & & saphyrus 45 & saphyrus 48 & \\
\hline Hyaena & $\mathrm{x} 44$ & & & & & hyenia 56 & x 42//49 & iena 46 & $\mathrm{x} 47$ & X 75 (116) \\
\hline Idaeus dactylus & & & & & & 1 & 1 & 1 & 1 & 1 \\
\hline Iris & $\mathrm{x} 47$ & & irisites & & & iris 55 & yris $41 / / 48$ & iyrim 47 & iris 49 & iris 108 (123) \\
\hline 1 & & & & & & cama 57 & & kauman 50 & kacaman 55 & kakma 78 \\
\hline Leucochrysus & & & & & & & & 1 & 1 & leochrysus 32 \\
\hline Lycophtalmus & & & & & & & & 1 & 1 & lycophthalinus 32 \\
\hline $\begin{array}{l}\text { Lychnites } \\
\text { (marmor) }\end{array}$ & & & $\mathrm{x}$ & & & zingnites 104 & //zignites 85 & zignites 82 & $\begin{array}{l}{ }^{19} \text { zignites } 98 \\
=\text { evas/lichinites } \\
79\end{array}$ & zignies 79 (117), 108 \\
\hline Lyncurius & ligurius 24 & $\mathrm{x}$ & lapis lyncis & $\mathrm{x}$ & & $\times 60$ & ligurius $44 \mathrm{XII} / / 50$ & lygurius 51 & ligurius 56 & lygurius 80 (117) \\
\hline Liparia & liparea 45 & 1 & 1 & & & lipparis 61 & liparea 43 & lypparia 52 & lippares 57 & lyparea 80 \\
\hline Magnes & x 19 & & $\mathrm{x}$ & $\mathrm{x}$ & $\mathrm{x}$ & $\begin{array}{l}\text { magnes } 63 \quad(\mathrm{cf} . \\
\text { adamas 9) }\end{array}$ & $\begin{array}{l}\text { magnes } 45 / / 52 \text { (cf. } \\
\text { adamas) }\end{array}$ & magnes 53 & $\begin{array}{l}\text { magnes } 58 \\
=\text { magnetes }\end{array}$ & 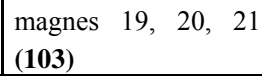 \\
\hline $\begin{array}{l}\text { Margarita } \\
\text { unio }\end{array}$ & $\begin{array}{l}x 50 \\
x\end{array}$ & & & & & margarita 62 & margarite (44) & margarita 54 & margarita 61 & \begin{tabular}{|l} 
margarita $81 \quad(118)$, \\
$82,83,84$ \\
unio 81,107
\end{tabular} \\
\hline $\begin{array}{l}\text { Marmor: } \\
\text { Alabastrites, } \\
\text { Augustaneum, }\end{array}$ & & & & & & & & & & $\begin{array}{l}\text { x } 15(\mathbf{1 0 2}) \\
\text { x } 16(\mathbf{1 0 2}) \\
/\end{array}$ \\
\hline
\end{tabular}

${ }^{19}$ Cette pierre est appelée ignites ou lychnites chez Damigéron. Sans voir le lien avec zignites, Vincent de Beauvais cite Isidore de Séville et Solin (lychynes), Pline (lychinites) et le cistercien Hélinand de Froidmont (lychines, d'après Isidore). Les propriétés médicales alléguées pour zignites et evas prévalent chez Vincent de Beauvais sur la description de la nature enflammée de la lignite qui était de mise dans l'Antiquité. 


\begin{tabular}{|l|l|l|l|l|l|l|l|l|l|l|}
\hline Basaltes, \\
Carystium, \\
Coraliticus, \\
Corinthaeus, \\
Ebur, \\
Lesbius, \\
Lucullaeum, \\
Lunensis, \\
Lygdinus, \\
Numidicum, \\
Porphyrites,
\end{tabular}


Isabelle DRAELANTS

\begin{tabular}{|c|c|c|c|c|c|c|c|c|c|c|}
\hline Melichrysus & & & & & & & & & & 1 \\
\hline Melitites & & & & & & & & & & ${ }^{20}$ melinus 28 \\
\hline Memphitis & & & & memphites & & memphites 65 & memphites $46 / / 53$ & & memphites 64 & memphites 27 (107) \\
\hline Mesomelas & & & & & & & & & & $\mathrm{x} 30$ \\
\hline Mithridax & & & & & & 1 & 1 & 1 & 1 & 1 \\
\hline Molochites & melochites 54 & $\mathrm{x}$ & & $\mathrm{x}$ & & merochites 68 & melonites 47 & $\mathrm{x} 56$ & melochites 63 & malachites 86 \\
\hline Molotius & 1 & & & & & 1 & 1 & 1 & 1 & 1 \\
\hline Murrina & 1 & & & & & & & $:$ & 1 & $\begin{array}{l}\text { murhina }=\text { muria } 86 \\
(\mathbf{1 1 9})\end{array}$ \\
\hline Myrrhites & 1 & & & & & & & & & $\mathrm{x} 36,85$ \\
\hline Myrmicites & 1 & & & & & & & & & $\mathrm{x} 32$, \\
\hline 1 & & & narcissites & & & & & & & \\
\hline \multirow[t]{2}{*}{$\begin{array}{l}\text { Nitrum }^{21} \\
\text { Hammites }\end{array}$} & 1 & & & & & $\begin{array}{l}\text { nitrum } 70 \\
/\end{array}$ & //nitrum 55 & $\begin{array}{l}\text { nitrum } 57 \\
/\end{array}$ & $\begin{array}{l}\text { nitrum } 65 \\
\text {, }\end{array}$ & $\begin{array}{l}\text { nitrum } 87 \\
/\end{array}$ \\
\hline & & & & & & batrachius 71 & $\begin{array}{l}\text { borax 12//13 } \\
\text { /nosech } 57 \\
\end{array}$ & nose 59 & $\begin{array}{l}\text { borax } 11 \\
\text { nuse } 67 \\
\end{array}$ & \begin{tabular}{|l|}
$\begin{array}{l}\text { borax } 49 \\
\text { nose }\end{array}$ \\
\end{tabular} \\
\hline Obsidius & 1 & & & & & & & 1 & 1 & 1 \\
\hline 1 & & & obsianus & & & & & & & \\
\hline \multirow[t]{2}{*}{ Onyx } & $\times 9$ & & & $\mathrm{x}$ & $\mathrm{x}$ & $\times 72$ & x $50 \mathrm{XII} / / 59$ & $\times 60$ & × 68 & x $87(\mathbf{1 1 9})$ \\
\hline & & & & & & & onichinus 49//58 & & onycha 69 & onichinus 87 (119) \\
\hline
\end{tabular}

${ }^{20}$ La citation est tirée de Pline, dont Isidore reprend les mots.

${ }^{21}$ Classé dans Gleba ex aqua, avec bitumen, alumen, sal, etc. 


\begin{tabular}{|c|c|c|c|c|c|c|c|c|c|}
\hline 1 & & & odontolycius & & & & & & \\
\hline Opalus & optallius 49 & & optallion & & $\mathrm{x} 63$ & $\begin{array}{l}\text { ostolanus / oltamus } \\
51 / / 60\end{array}$ & optallius 61 & ophthalmus 70 & $\mathrm{x}$ / ophthalis 88 \\
\hline Ostracites & 1 & & & & & & & & $\times 89$ \\
\hline Orca & 1 & & & & 1 & 1 & 1 & 1 & 1 \\
\hline 1 & orites 43 & 1 & $\mathrm{x}$ & & orites 74 & orites $52 / / 61$ & orites 62 & oristes 71 & orithes 89 \\
\hline 1 & & & & & & & & orphanus 72 & \\
\hline Paederos & & & & & 1 & 1 & 1 & 1 & pedoros 91 \\
\hline Panchrus & panteron 51 & & $\mathrm{x}$ & & panchrus 80 & panthera $54 / / 63$ & pantherus 63 & pantherus 73 & pantherus 90 (119) \\
\hline & peanites 34 & $\mathrm{x}$ & & & peantides 79 & peantides 79 & peanites 64 & peranites 74 & peanites 90 \\
\hline Phengites & & & & & & & & & $\times 25$ \\
\hline Phlogites & & & & & & & & & $\begin{array}{l}\text { flongites / phlegontes } \\
72\end{array}$ \\
\hline 1 & & & phoenicites & & & & & & \\
\hline Phrygius $^{22}$ & & & & defriges & & & & & $\begin{array}{ll}x & 25 \\
\text { fingites/frigius })\end{array}$ \\
\hline Pontica & & & & & & & & & $\times 30$ \\
\hline $\begin{array}{l}\text { (Parsius) } \\
\text { Prasius }\end{array}$ & $\mathrm{x} 40$ & & & & x 77 & $\mathrm{x} 55 / / 64$ & prassius 65 & prassius 76 & x 91 \\
\hline 1 & & & polyzonus & & & & & & \\
\hline Pulvis, Gleba : & & & & & 1 & 23 & & & pulvis, gleba VI, 66 \\
\hline
\end{tabular}

${ }^{22}$ Ce nom est lié chez Dioscorides à la pyrite, aussi appelée defriges. 


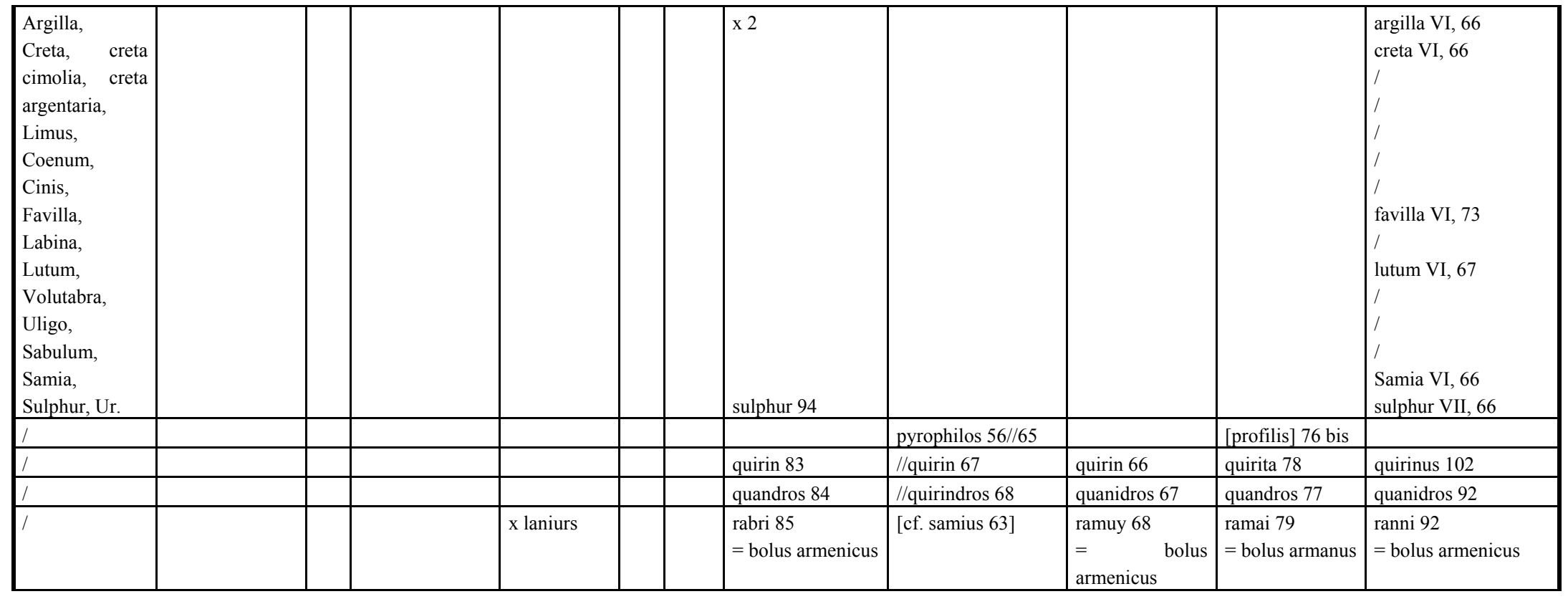

${ }^{23}$ Chez Thomas de Cantimpré, aucune de ces substances ne fait l'objet d'une notice, mais elles interviennent pour la plupart à l'intérieur de prescriptions pharmacologiques, médicinales, sans être empruntées au texte d'Isidore. 


\begin{tabular}{|c|c|c|c|c|c|c|c|c|c|c|}
\hline / & & & & & & & & $\begin{array}{|lr|}\begin{array}{l}\text { radaym } \\
=\text { donatites }\end{array} & 69 \\
\end{array}$ & $\begin{array}{l}\text { radaim } 79 \\
=\text { donatites }\end{array}$ & $\begin{array}{l}\text { raday } 92 \\
=\text { donatides }\end{array}$ \\
\hline Rhodites & & & & & & 1 & 1 & 1 & 1 & 1 \\
\hline Rudos & & & & & & 1 & 1 & 1 & 1 & 1 \\
\hline Sabinus & & & & & & & & & & ${ }^{24} \mathrm{x} 4$ \\
\hline $\begin{array}{l}\text { Terra samia } \\
\text { (cf. pulvis) }\end{array}$ & & & & & & [v. rabri] & samius $63 / / 75$ & & $\begin{array}{llll}\begin{array}{l}\text { samius } \\
\text { ramai] }\end{array} & 86 & \text { [v. } \\
\end{array}$ & $\begin{array}{l}\text { samius } 26 \text { [v. ranny] } \\
(\mathbf{1 0 7})\end{array}$ \\
\hline Sandasirus & & & & & & & & 1 & 1 & $\mathrm{x} 36,95$ \\
\hline $\begin{array}{l}\text { Saphirus } \\
\text { syrtites }\end{array}$ & x 5 & & $\begin{array}{l}\text { syrtius } 22 \\
\text { colluro } 38 \\
\end{array}$ & $\mathrm{x}$ & & $\begin{array}{l}x 87 \\
=x\end{array}$ & x $57 \mathrm{XII} / / 69$ & $\begin{array}{l}x 70 \\
=x\end{array}$ & $\begin{array}{l}\text { x } 81 / \\
=\text { sirites } / \text { sirtites }\end{array}$ & x 93, $94(\mathbf{1 2 0}) /$ x 98 \\
\hline Sardonyx & x 8 & & & & & x 90 & sardonix 59//71 & sardonycen 71 & $\begin{array}{l}\text { x } 85 \\
=\text { sardonycem }\end{array}$ & $\begin{array}{l}\begin{array}{l}x \quad / \quad \text { sardonychus } \\
97(\mathbf{1 2 0})\end{array} \\
\end{array}$ \\
\hline Sarcophagus & & & & & & & $\times 62 / / 74$ & & $\mathrm{x} 82$ & $\mathrm{x} 4,26(\mathbf{1 0 7})$ \\
\hline Sagda & x 35 & $\mathrm{x}$ & & & & & sarda $67 / / 79$ & sadda 73 & $\begin{array}{l}\text { sarda } \\
=\text { sardo } 83\end{array}$ & x 95 (120) \\
\hline Sardius & $\mathrm{x} 10$ & & sardo & & $\mathrm{x}$ & $=$ sarda 89 & $\mathrm{x} 60 \mathrm{XII} / / 72$ & $\times 72$ & sardinus 84 & x $96(\mathbf{1 2 0})$ \\
\hline $\begin{array}{l}\text { Saxum, } \\
\text { Scopulus, } \\
\text { Spelunca, } \\
\text { Crepido, Echo, } \\
\text { Calculus, }\end{array}$ & & & & & & $\cos 23$ & & & & $\begin{array}{l}\text { saxum } 6(\mathbf{1 0 1}) \\
\cos 6,14(\mathbf{1 0 1}) \\
\text { pumex }(\mathbf{1 0 1})\end{array}$ \\
\hline
\end{tabular}

${ }^{24}$ Cite Pline, dont les mots sont repris par Isidore. 
Isabelle DRAELANTS

\begin{tabular}{|c|c|c|c|c|c|c|c|c|c|c|}
\hline $\begin{array}{l}\text { Scrupulum, } \\
\text { Cos, Pumex, } \\
\text { Rudos, } \\
\text { Gypsum, Calx, } \\
\text { Arena }^{25}\end{array}$ & & & & & & & & & & \\
\hline Selenites & silenites 26 & & selenitis & $\mathrm{x}$ & & selenites 92 & $\begin{array}{l}\text { sylonites } 66 / / 77 \text { [v. } \\
\text { celonites] }\end{array}$ & sylenites 74 & $\begin{array}{l}\text { silenites } 87 \text { [v. } \\
\text { celonites] }\end{array}$ & \begin{tabular}{|l|}
$\begin{array}{l}{ }^{26} \text { selenites/silenites } \\
\text { chelonites } 98(\mathbf{1 2 0})\end{array}$ \\
\end{tabular} \\
\hline Schistos & & & $\mathrm{x}$ & & & & $\begin{array}{lll}\begin{array}{l}\text { iscistos } \\
\text { cegolitus })\end{array} & & \end{array}$ & & $\begin{array}{l}\text { iscustos } 50 \\
=\quad \text { carbunculus } \\
\text { albus }\end{array}$ & $\left({ }^{27}\right.$ schistos 69) \\
\hline Sideritis & & & & & & & & & & $\left({ }^{28}\right.$ sideritis 19,40$)$ \\
\hline Scorpitis & & & & & & & & & & 1 \\
\hline Siphinius & & & & & & & & & & 1 \\
\hline Silex & & & & & & & & & & x 13 (101) \\
\hline $\begin{array}{l}\text { Smaragdus } \\
\text { Chalchosmarag } \\
\text { dus }\end{array}$ & $\mathrm{x} 7$ & $\mathrm{x}$ & $\mathrm{x}$ & & $\mathrm{x}$ & x 88 & x $58 \mathrm{XII} / / 70$ & x 75 & x 88 & $\begin{array}{l}\text { x } 99 \text { (121), 100, 101, } \\
102\end{array}$ \\
\hline Smyris & & & & & & & & & & 1 \\
\hline
\end{tabular}

${ }^{25}$ Classés dans les lapides vulgares.

${ }^{26}$ Vincent de Beauvais a noté la confusion entre la celonites et la selenites: Auctor. Ista duo vocabula gemmarum chelonites, et selenites videntur confundi : et unum pro alio sumi, ac vitio scriptorum alterutrum corrumpi. nam eadem ex parte hic dicuntur de Selenite, que superius dicta sunt de chelonite.

${ }^{27}$ Seulement dans une citation de Pline sur les sortes différentes d'hématite.

${ }^{28}$ Dans le chap. 40, à l'intérieur d'une citation de Pline à propos des variétés d'adamas, et dans le chap. 19, à propos des sortes de magnes. 


\begin{tabular}{|c|c|c|c|c|c|c|c|}
\hline Solis gemma & & & $\mathrm{x} 91$ & & & & (x 36) 103 \\
\hline Specularis & & & & $\times 55 / / 78$ & & $\mathrm{x} 89$ & $\left({ }^{29} \mathrm{x} 4,82\right)$ \\
\hline 1 & & steatites & & & & & \\
\hline Synochitide & & & & & & & (x 32) \\
\hline Syrius & & & & $\mathrm{x} 61 / / 73$ & & $\begin{array}{l}\text { syrium / syrus } \\
90\end{array}$ & $28(107)$ \\
\hline \multicolumn{8}{|l|}{ Taos } \\
\hline Thebaicus & & & & & & & $\left({ }^{30} \times 3\right)$ \\
\hline Thyites & & & & & & & 1 \\
\hline Topazion & $\mathrm{x} 13$ & $\mathrm{x}$ & topazius 96 & topasius $68 \mathrm{XII} / / 80$ & x $76(+\mathrm{IV})$ & $\times 92$ & topazius $106 \mathbf{( 1 2 3 )}$ \\
\hline 1 & & triglites & & & & & \\
\hline Trychrus & & & & & & & 1 \\
\hline 1 & & & turchogis 97 & & turcoys 77 & turchoix 93 & turcois 106 \\
\hline Tusculanus & & & & & & & 1 \\
\hline Thracius & & & & & & & 1 \\
\hline $\begin{array}{l}\text { [cf. } \\
\text { draconitides] }\end{array}$ & & & & & ${ }^{31}$ varach 78 & varach 94 & varach 107 \\
\hline
\end{tabular}

${ }^{29}$ Dans des citations de Pline.

${ }^{30}$ Dans une citation de Pline.

${ }^{31}$ Varach, id est sanguis draconis (recopié par Albert le Grand et Vincent de Beauvais, qui indiquent pour source «Aristote ». Il n'est pas impossible que « Ar. » désigne Aaron, noté par Arnold de Saxe dans son prologue comme source principale, avec Evax et Aristote). Sang dragon : suc, gomme, résineux rouge. Cette pierre fait partie de la tradition hermétique des Kyranides [Kyranides, I, phi, éd. L. Delatte, Textes latins et vieux français relatifs aux Cyranides, Liège-Paris, 1942 (Bibliothèque de la Faculté de Philosophie et lettres de l'Univ. de Liège, fasc. 93), p. 11-206, ici p. 85, 1. 11- 86, 1. 5] et se retrouve par suite dans le Liber de 


\begin{tabular}{|c|c|c|c|c|c|c|c|c|c|}
\hline Veientana & & & & & & & & & (x 30) \\
\hline Veneris crinis & & & & & & & & & $(\mathrm{x} 30,36)$ \\
\hline 1 & & & & & & $/ /$ vernix 82 & vernix 79 & vernix 95 & \\
\hline pyrites & pirites 56 & & $\mathrm{x}$ & $\mathrm{x}$ & x 78 & $\begin{array}{l}\text { perites } \\
=\text { peridonius } 53 / / 62\end{array}$ & virites $80(+\mathrm{IV})$ & $\begin{array}{l}\text { perithes } 75 \\
=\text { peridonius }\end{array}$ & x 24 (107) \\
\hline cyanea & & $\mathrm{x}$ & & & $\begin{array}{l}\text { zimiech } 103 \\
=\text { lapis lasurii }\end{array}$ & $\begin{array}{l}\text { //zunich vel lapis } \\
\text { lazurii } 84\end{array}$ & zimech 81 & $\begin{array}{l}\text { zemech } 97 \\
=\text { lapis lazuli }\end{array}$ & zimen vel lazuri 102 \\
\hline $\begin{array}{l}\text { Zmilaces } \\
\text { Arabica }\end{array}$ & & & & & & & & & 1 \\
\hline
\end{tabular}

virtutibus herbarum, lapidum et animalium. Cf. I. Draelants, Le Liber de virtutibus herbarum, lapidum et animalium (Liber aggregationis), Un texte à succès attribué à Albert le Grand, Firenze, 2007 (Micrologus Library, 22), p. 335-36 et p. 424-25. 
Dans la comparaison qui précède, ce qui frappe au premier regard est une certaine communauté de documentation: excepté celles dues exclusivement à Isidore, une grande part des pierres qui font l'objet d'une notice sont communes à tous les naturalistes du XIII ${ }^{\mathfrak{e}}$ siècle, car elles sont empruntés au Liber lapidum de Marbode de Rennes. On note également l'inflation de la documentation chez Vincent de Beauvais, qui cumule l'ensemble des sources d'information, provoquant, malgré sa vigilance et par respect pour ses auctoritates, une inévitable redondance dans les notices et certains doublons dans le traitement de la même substance minérale. Cette redondance est d'autant plus considérable qu'elle existe dès les premières compilations consacrées aux pierres. Les aléas de la transmission ont ainsi souvent eu pour effet qu'une même substance finisse par donner lieu à deux notices différentes - ou davantage - sous des noms déformés.

Il est aussi notable que l'influence directe d'Isidore est absente dans le lapidaire d'Arnold de Saxe, dont l'originalité n'est plus à démontrer'. Son intention était d'exposer une documentation la plus aristotélicienne possible, en mettant à profit toutes les sources qui pouvaient livrer des bribes de la minéralogie du Stagirite, un objectif qu'Albert le Grand reprendra complètement à son compte. Cela, d'autant plus que la source essentielle du De mineralibus d'Albert, pour le deuxième traité, est précisément le catalogue alphabétique d'Arnold de Saxe, que celui-ci dit avoir composé à partir d'Aristote, d'Evax et Aaron.

En revanche, l'adoption systématique du livre XVI des Étymologies d'Isidore de Séville au titre de source documentaire est une caractéristique de Barthélemy l'Anglais, Vincent de Beauvais et, dans une moindre mesure, de Thomas de Cantimpré. Elle justifie la présence, chez ces auteurs, de certaines pierres qui ne se trouvent pas dans les autres sources employées par les encyclopédistes: iudaicus (alors qu'il s'agit de la pierre traitée aussi sous cegolitus), syrium, sarcophagius, succinus, specularis, toutes reprises indirectement par Albert le Grand, à travers son emploi du Liber de natura rerum de Thomas de Cantimpré. Si Vincent de Beauvais inclut ces notices également, c'est pour répéter de même les dires de Thomas. Chez Barthélemy, on peut y ajouter asyctos, argirites, astrion, asteria, amatides, cos, gemma, melitites, meroctes, marmor, petra, parius, solis, sulphur, et chez Vincent phrygius, phengites/phlegontes/flongites, cos, marmor (le marbre intervient sous divers noms dans plusieurs notices), absyctos, asterites, astrion, callaica, chrysocolla, chrysolansis, ephestis, egyptilla, emistio, hyacinthizonta, lychynes, ostracites, pedoros, pontica, sandasirus, solis, veientana, que les autres encyclopédistes n'ont pas retenues des Étymologies.

La notice sur la memphites est aussi empruntée par Albert à Thomas de Cantimpré qui l'avait trouvée chez Isidore. Par ailleurs, amiantos semble isolée chez Thomas de Cantimpré, mais elle se trouve dans la materia medica de Dioscoride, chez Pline et Isidore ${ }^{2}$. Elle correspond, chez les autres encyclopédistes du XIII ${ }^{\mathrm{e}}$ siècle, à amandinus. Il en va de même pour Iscustos, que Thomas de Cantimpré (à qui Albert emprunte la notice) emprunte à Isidore, mais qui se trouve déjà chez Dioscoride.

\footnotetext{
${ }^{1}$ Cf. I. Draelants, « La science encyclopédique des pierres », op. cit.

${ }^{2}$ Pline, Historia Naturalis, XXXVI, 139 et Isidore, Étymologies, XVI, 4, 19.
} 
La plupart de ces pierres qu'on pourrait croire empruntées seulement à Isidore figurent initialement dans la Materia medica de Dioscoride, que Barthélemy a également utilisée de première main. Vincent de Beauvais reprend aussi chez Dioscoride les corps agapis (c. 42), asius (c. 46), cynedia (c. 44), qu'il met sous le nom d'Isidore, ainsi que (ex)ebenus. Certaines notices, présentes chez Barthélemy et Thomas, ont été négligées par Vincent de Beauvais ou Albert; elles se révèlent être tirées aussi d'une version de la Materia medica de Dioscoride et concernent les pierres auripigmentum, iudaicus, memphites, samius.

Notons aussi que l'onichinus, présent seulement chez Thomas, est un doublet d'onyx, qu'Albert le Grand a éliminé. Thomas de Cantimpré avait probablement introduit onichinus parce qu'il faisait partie des XII pierres du lapidaire chrétien, dont il inclut la matière. De temps à autre, et dans les rares cas où la nouvelle nomenclature minéralogique le permet, Thomas allie à ces autorités chrétiennes des extraits de la Glose ${ }^{3}$, de saint Augustin ${ }^{4}$, et, bien sûr, de Plines.

Une nouvelle version latine de la minéralogie de Dioscoride, effectuée fin XI siècle, début $\mathrm{XII}^{\mathrm{e}}$, eut un succès considérable dans tout l'Occident. On l'appelle «Dioscoride alphabétique». On a pensé qu'elle pouvait avoir été ordonnée alphabétiquement par Constantin l'Africain, car certains ajouts sont en rapport avec ses autres traductions ${ }^{6}$. Les additions propres à cette version originaire d'un milieu monastique sont des extraits de Gargilius Martialis, du Pseudo-Apulée, de PseudoOribase, d'Isidore, de Galien et d'autres auteurs. Cette version de Dioscoride inclut, dans la section minéralogique, le texte du Damigéron-Evax sur les pierres, pour les minéraux mentionnés dans la Materia medica de Dioscoride. C'est probablement devant un tel texte, mêlant Evax et Dioscoride, que Barthélemy l'Anglais ${ }^{7}$ et Arnold de Saxe se sont trouvés pour rédiger leurs catalogues de pierres. Beaucoup de manuscrits contenant le Liber lapidum de Marbode comprenaient aussi le lapidaire d'Evax-Damigéron, parfois copié en marge du texte de Marbode. Arnold de Saxe a utilisé probablement exemplaire de ce genre du De lapidibus de Marbode additionné d'extraits du Damigéron-Evax alphabétique. Ce n'est pas la même version de Dioscoride, ni de Marbode, qui a été vue par Vincent de Beauvais ${ }^{8}$.

Certains minéraux, non représentés chez Isidore, se trouvent donc ajoutés chez les lapidaristes et encyclopédistes du XIII ${ }^{\mathrm{e}}$ siècle, ou déjà chez Marbode de Rennes. Dans ce cas, la source de Marbode peut être Pline, ou Solin (qui rapporte Pline, comme dans le cas de peanites), ou encore Damigeron-Evax. En effet, le lapidaire de Marbode, terminé probablement en 1096, fut constitué sur la base de

\footnotetext{
${ }^{3}$ Liber de natura rerum, XIV, 49, onichinus : glosa super Leviticum (p. 365, 1. 2), glosa in loco Exodi (p. 366, 1. 14), 60, sardius : glosa (p. 368, 1. 4).

${ }^{4}$ Liber de natura rerum, XIV, 45, magnes (p. 365, 1. 16).

${ }^{5}$ Exemples d'emplois par Thomas de Cantimpré : Liber de natura rerum, XIV, 44 (ligurius), 68 (topasius).

6 Ed. «Dioscoride alphabétique»: Dioscoridis exactissimi indagatoris fidelissimique scriptoris virtutem simplicium medicinarum Liber, ccccccxvij continens capitula: cum nonnullis additionibus Petri paduensis..., Lyon, per Gilbertum de villiers, 1512.

${ }^{7}$ C'est ce qu'avançait déjà pour Barthélemy L. Thorndike, A History of Magic, t. 2, p. 401403.

${ }^{8}$ Contrairement à ce que pensait L. Thorndike, A History of Magic, t. 2, p. 457.
} 
Pline, Solin, Bède, et surtout le livre XVI des Étymologies. Par ailleurs, pour expliquer certaines similitudes avec ce qu'on a gardé du lapidaire d'Aristote, on a dit que Marbode avait utilisé une traduction latine du De physicis ligaturis de Qustâ ibn Lûqâ, qu'il aurait pu consulter dans une copie anonyme peu après sa traduction en latin. Quoi qu'il en soit, la source essentielle de Marbode est le Damigéron-Evax latin, qui transmet une matière analogue à la matière présumée du De lapidibus d'Aristote.

Il existait aussi, à l'époque de Marbode au plus tard, des lapidaires qui mêlaient au texte de Damigéron-Evax, sur les propriétés des pierres, les descriptions tirées des Étymologies d'Isidore. En témoigne, entre autres, le manuscrit Paris, B.n.F. lat. 7028, du XI ${ }^{\mathrm{e}}$ siècle, originaire de Saint-Hilaire de Poitiers. Il contient ces extraits, enchâssés dans une copie des Dunamidia pseudo-galéniques?

D'autres textes sur les pierres, moins connus et moins répandus, ont également contribué à enrichir la matière minéralogique. C'est le cas de l'Epistola regis Aegypti ad imperatorem Octavianum, éditée par J.Pitra ${ }^{10}$. Connue des médecins salernitains au XII ${ }^{\mathrm{e}}$ siècle, elle est copiée dans notamment le manuscrit Cava, Archivio e Bibl. della Badia 3, qui contient le De temporibus de Bède, des extraits d'Isidore sur les gemmes, suivis du texte latin du lapidaire de DamigéronEvax. Ce texte a servi à Thomas de Cantimpré, dans la deuxième version du De lapidibus compris dans le Liber de natura rerum, à propos du pyrophilus ${ }^{11}$ :

Pyrophilos lapis est pretiosissimus, ut narrat scriptura Esculapii philosophi ad Octauianum Augustum missa. Dicit enim : Cor hominis ueneno perempti non potest

Par la suite, cette notice a été empruntée par Albert le Grand à Thomas de Cantimpré.

Barthélemy l'Anglais semble, comme Vincent de Beauvais, animé par une volonté d'exhaustivité. En effet, près de quarante substances supplémentaires se trouvent dans son catalogue alphabétique par rapport à celui de ses contemporains. Il s'agit de métaux ou de substances utiles à l'alchimie, que Barthélemy a trouvées la plupart du temps chez Avicenne (De congelatione et conglutinatione lapidum, c'està-dire ce qui est transmis comme le livre IV des Météorologiques d'Aristote) ou dans un Liber alchemie attribué à Hermès ${ }^{12}$. Il dit cependant avoir trouvé certaines pierres chez Isidore de Séville, dont il dépend davantage que les autres encyclopédistes en cette matière. Voici la liste de ces trente-neuf minéraux, où nous rendons en caractères droits ce que Barthélemy dit devoir à Isidore, même si certaines de ces notices ne se trouvent que dans la Materia medica de Dioscoride : Arena, c. 1; Argella, c. 2; Aurum, c. 4;Aurichalcum, c. 5;Argentum, c. 7 ; Argentum vivum, c. 8 ; Asyctos, c. 13; Argirites, c. 15; Astrion, c. 16; Asteria, c. 18 ; Amatides, c. 19 ; Bitumen, c. 20 ; Calculus, c. 22 ; Cos, c. 23 ; Calx, c. 24 ; Camentum, c. 25 , es, c. 37 , Electrum, c. 38 , Ferrum, c. 45 ; Ferrugo, c. 46 ; Gleba,

\footnotetext{
${ }^{9}$ A. Beccaria, I codici di medicina del periodo presalernitano, Roma, 1956, p. 152-56.

${ }^{10}$ J. Pitra, Analecta Sacra, t. 2, Tusculum, 1884, p. 641 sq.

${ }^{11}$ Ed. H. Boese, op. cit., p. 367.

${ }^{12}$ Ces deux sources sont également présentes dans le De floribus rerum naturalium d'Arnold de Saxe, mais dans la partie I (De celo et mundo), au livre V, et non dans le lapidaire qui constitue la IIIe partie du De floribus.
} 
c. 47 ; Gemma, c. 48 ; Melitites, c. 64 ; Myrrhite, c. 66 ; Meroctes, c. 68 ; Marmor, c. 69 ; Petra, c. 75 ; Parius, c. 76 ; Plumbum, c. 81 ; Pulvis, c. 82 ; Rosten/reiben ${ }^{13}$ c. 86 ; Solis gemma, c. 91; Stannum, c. 93; Sulphur, c. 94; Sal, c. 95; Terra sigillata, c. 98 ; Tartarum, c. 99 ; Vitrum, c. 100, Idachites, c. 101 [doublet pour enhydros].

Les sources de Barthélemy sont donc nombreuses. À Pline et Isidore s'ajoutent Marbode et Dioscoride en plusieurs versions pour ce dernier, ainsi que les traités médicaux de Platearius et Constantin, et, nous l'avons dit, l'alchimie d'Avicenne et d'Hermès, mais aussi la jeune traduction des Météorologiques d'Aristote. Les Pères de l'Église ne sont pas oubliés, Augustin et Grégoire en particulier. Sur toutes ces autorités, les Étymologies d'Isidore dominent. Barthélemy devait disposer sans doute d'un exemplaire complet des Étymologies, car il prend soin de donner les références précises aux livres et aux chapitres de cet ouvrage. Cette source est suivie de près par le Liber lapidum de Marbode cité souvent en vers, avec la référence «in lapidario», sans nom d'auteur. Sous ce même marqueur apparaissent parfois des passages en prose, ce qui prouve que Barthélemy se trouvait devant un texte composite du Liber lapidum.

L'exemple suivant illustre le constat du rôle de source centrale du Liber lapidum de Marbode, complété chez Barthélemy par la référence redondante à Isidore et à Dioscoride :

\begin{tabular}{|l|l|}
\hline Arnold de Saxe, DFRN III, I, 72 & Barthélemy l'Anglais, DPR, XVI, c. 89, p. \\
$\mathbf{7 6 2}$
\end{tabular}

Barthélemy distingue clairement le texte dioscoridien du lapidaire d'Isidore et de Marbode, car il juxtapose parfois l'opinion de l'un et de l'autre, comme dans la notice sur le corail, où l'on reconnaît la source commune chez Arnold de Saxe :

\footnotetext{
${ }^{13}$ Ce minéral a un nom emprunté à l'allemand; il est probable que Barthélemy rapporte une connaissance acquise dans la région de Magdeburg, où les mines et les richesses du sol étaient nombreuses (il le dit lui-même dans la partie géographique de son encyclopédie).

${ }^{14}$ Cette dernière phrase est un ajout dans le texte de Marbode, propre à la famille $\delta$ des manuscrits.
} 


\begin{tabular}{|c|c|}
\hline A.S., DFRN III, I, 19 & B.A., DPR, XVI, c. 33, p. 732 \\
\hline $\begin{array}{l}\text { Corallus lapis est, due sunt } \\
\text { species rufus et albus. Est } \\
\text { sicut ramusculus, trahitur a } \\
\text { mari, valet contra quemlibet } \\
\text { fluxum sanguinis et } \\
\text { epylenciam et contra uana } \\
\text { monstra collo suspensus et } \\
\text { demoniaca et fulmina et } \\
\text { contra tempestates et } \\
\text { grandines. Et aspersus fructus } \\
\text { multiplicat, et expedit } \\
\text { principia et fines negotiorum. }\end{array}$ & $\begin{array}{l}\text { Coralium nascitur in mari rubro, et quandium tegitur aquis, } \\
\text { [...] ut dicit Isidorus capit. de rubris gemmis. Et sequitur } \\
\text { ibidem, quantum apud nos preciosa est Indica margarita, } \\
\text { tanto preciosior est coralium apud Indos. Hoc magi dicunt } \\
\text { resistere contra fulmen. Isidorus. Idem dicitur in lapidario. } \\
\text { [= Liber lapidum, Marbode] } \\
\text { Ipsius est, ut ait Zoroastes, mira postestas./ Fulmina, } \\
\text { riphones, tempestatesque repellit /... A quocunque geratur. } \\
\text { Est autem duplex, albus et rufus, et nunquam ultra } \\
\text { semipedem longior inuenitur. Rufus maxime valet contra } \\
\text { omnem fluxum sanguinis, contra epilepsiam et contra } \\
\text { diabolica et uaria monstra, multiplicat fructus et expedit } \\
\text { fines et principia negociorum. }\end{array}$ \\
\hline
\end{tabular}

Les choses sont différentes pour le Speculum naturale. Dans le tableau comparatif général ci-dessus, la liste de minéraux du Speculum naturale se fonde sur les deux versions, bifaria (avant 1244) et trifaria (c. 1259) du Speculum maius. La version du Speculum naturale appelée bifaria est parfaitement contemporaine du travail de documentation mené par Barthélemy l'Anglais, Thomas de Cantimpré et Arnold de Saxe. Elle a mis à profit une documentation collectée dans des bibliothèques du nord de la France. Il ne subsiste à l'heure actuelle que deux manuscrits incomplets de cet texte du naturale $^{15}$, qui donnent à connaître la table des matières des treize premiers livres, la description du contenu du total des trente livres, et le texte des livres I à VIII. Ce premier speculum naturale développe l'histoire naturelle d'après le récit de la Genèse, la description des propriétés des choses, la chute de l'homme et le péché, pour terminer par les sciences, les arts et les vertus comme moyens de salut. La tradition manuscrite a heureusement conservé le chapitre concernant les pierres de cette première version du Speculum naturale. Nous en avons publié ailleurs les rubriques et la liste des sources pour les livres

${ }^{15}$ Il subsiste au moins vingt-cinq exemplaires manuscrits du Naturale. Les deux qui conservent la version bifaria se trouvent à Bruxelles, Bibliothèque royale Albert $1^{\mathrm{er}}, 18465$ (provenance: abbaye de Saint-Martin de Tournai, ca. 1270-1280, conservant l'introduction générale au Speculum maius appelée liber apologeticus, les livres I-VIII et la table de ces livres) et Bruxelles, B.R. 9152 (provenance : Saint-Laurent de Liège, XV ${ }^{\mathrm{e}}$ s., conservant la même introduction, les livres I-VII et la table des livres I-XIII); cf. M. Paulmier-Foucart, "Étude sur l'état des connaissances au milieu du XIII ${ }^{\mathrm{e}}$ siècle : nouvelles recherches sur la genèse du Speculum maius de Vincent de Beauvais ", Spicae. Cahiers de l'Atelier Vincent de Beauvais, 1 (1978), p. 91-122, qui décrit pour la première fois le manuscrit de Bruxelles, et H. Voorbij, Het Speculum Historiale van Vincent van Beauvais. Een studie van zijn ontstaansgeschiedenis, Groningen, 1991, p. 330-35. La liste complète et actualisée des manuscrits du Speculum naturale se trouve également dans la récente thèse d'Eva Albrecht, qu'il ne nous a pas été permis de consulter: De ontstaansgeschiedenis en de compilatie van het Speculum naturale van Vincent van Beauvais (= 1264), 2 vol., Katholieke Universiteit Leuven, 2007. 
consacrés aux pierres ${ }^{16}$, c'est pourquoi n'insisterons ici que sur la contribution de la documentation isidorienne dans ce premier état du Speculum naturale.

La description de la terre et du règne minéral intervient, dans ce Speculum naturale primitif, au livre $\mathrm{V}$, qui concerne l'œuvre du troisième jour (la terre) ${ }^{17}$. Ce livre compte 133 chapitres, où les chapitres 78 à 123 sont consacrés à des substances métalliques et minérales particulières. Le premier préfigure tous les autres : De hiis que continentur in visceribus terre. Il est précédé de développements sur l'eau comme élément et d'exposés sur les aluns et sels considérés comme minéraux, ainsi que de chapitres sur le quatrième élément, la terre. Ce sont les chapitres 78 à 123 qui connaîtront un développement très important dans la version trifaria, avec l'apport important des lapidaires alphabétiques d'Arnold de Saxe et de Thomas de Cantimpré. La matière de ces chapitres, modifiée dans l'exposition, prendra ainsi place aux livres VI, VII et VIII du nouveau Speculum naturale, où seront traités les substances issues de l'eau et de la terre, selon un schéma tripartite: minerae (minéraux, aluns, VI) - metalla (VII) - lapides (pierres et cailloux, VIII).

La documentation de cette version bifaria du livre des pierres partage la même tradition de science naturelle héritière de Pline, Augustin, Solin et Isidore que celle observée chez Thomas de Cantimpré et Barthélemy l'Anglais. Les livres XVI et XIX des Étymologies y sont extensivement mis à profit, Pline intervient de temps à autre, Solin est plus fréquent et il est complété si nécessaire par le Physiologus, cet ancêtre célébrissime des bestiaires médiévaux. D'Augustin, Vincent de Beauvais a emprunté (au c. 104) une grande partie du passage de la Cité de Dieu (livre 21) sur l'aimant, qu'il reprendra dans la version trifaria. Quant au Dyascorides utilisé dans la version bifaria, il n'intervient pas seulement dans le livre des pierres, mais aussi régulièrement à propos des plantes (bifaria, livre VI; trifaria, livres IX et X dans l'édition de Douai); selon toute apparence, il s'agit du texte de pharmacopée de la Materia medica, et non d'un lapidaire formé d'extraits de Dioscoride mêlés éventuellements à ceux d'Evax-Damigéron, comme c'est le cas chez Barthélemy et chez Arnold de Saxe. Les sources plus récentes sont Platearius, De simplici medicina, le Canon d'Avicenne, le traité in Almansorem de Rhazès, le De gradibus de Constantin. La plupart de ces extraits seront conservés dans la version ultérieure du Naturale.

Les marqueurs et les pierres traités dans les chapitres 101 à 123 du livre X, qui se consacrent à des pierres en particulier plutôt qu'à des exposés généraux ou à des métaux ${ }^{18}$, signalent précisément les livres ou les chapitres de l'œuvre dont les extraits sont tirés, en tout cas lorsqu'il s'agit d'Isidore, de Pline et de la Chronique d'Hélinand de Froidmont. Sur ces vingt-deux chapitres, comptant quatre-vingt-dixhuit marqueurs, Isidore est nommé trente-cinq fois (auxquelles il faut ajouter six marqueurs à restituer), c'est-à-dire qu'il occupe quarante pour cent de la documentation. En outre, le chapitre 108, tiré du passage d'Isidore sur les pierres précieuses, a été recomposé à partir d'un originale d'Isidore avant d'être réparti en trois chapitres $(29,32,33)$ dans la version trifaria.

\footnotetext{
${ }^{16}$ I. Draelants, «La science encyclopédique des pierres au XIII ${ }^{\mathrm{e}}$ siècle », (op. cit.), annexes.

${ }^{17}$ La table des matières de ce livre se trouve aux f. 8r-v du manuscrit Bruxelles, B.R., 18465 :

Quintus agit de inicio operis tercie diei. idest de dispositione partium inferiorum huius mundi.

${ }^{18}$ Voir l'annexe de l'article cité plus haut, La science encyclopédique des pierres.
} 
Il faut noter également que Vincent de Beauvais, dans cette première version du Speculum naturale, ne fait pas usage de première main du principal traité qu'on s'attendrait à trouver sous une telle rubrique, à savoir le lapidaire de Marbode de Rennes - quelle qu'en soit la version, interpolée ou non -, sur lequel se fondent ses contemporains encyclopédistes; il l'ignore sans doute encore à ce stade de la rédaction.

En revanche, dans la version trifaria conservée dans l'édition de Douai de 1624 , le catalogue alphabétique des pierres ne commence qu'au chapitre 36 du livre VIII, entièrement consacré aux minéraux : dicto de gemmis in generali, nunc restat dicendum de singulis secundum ordinem alphabeti. Vincent de Beauvais n'en consacre pas moins plusieurs notices, dans celles qui précèdent, à des pierres aux propriétés spectaculaires (l'aimant naturel), dont il reparlera ensuite ; il s'y intéresse aussi à des substances trouvées dans une documentation qui ne lui servira plus beaucoup dans le catalogue alphabétique des pierres. Les chapitres 1 à 36 s'intéressent ainsi à des corps comme la chaux, le tuf, la silice, le marbre ou le sable, qui sont intégrés systématiquement dans le catalogue chez Barthélemy, mais qui se trouvent dans des chapitres spécifiques chez Albert le Grand. La matière qu'on trouvait au livre V dans la version bifaria se trouve distribuée en trois livres: VI. De terra nudatione ac de huius elementi natura, VII. De corporibus quae continentur in terrae visceribus, VIII. De lapidibus. Cette inflation correspond à un développement exagéré de l'oeuvre du troisième jour, que Vincent de Beauvais confessait déjà dans la version du Liber apologeticus qui précède le Speculum naturale (bifaria) dans le manuscrit de Saint-Martin de Tournai ${ }^{19}$. En effet, dans la version bifaria, un seul livre est consacré à l'œuvre des autres jours, tandis que l'œuvre du troisième jour, qui concerne la terre, avait déjà occupé trois livres (qui deviendront dix dans la version trifaria). Sauf à perdre toute adéquation à l'esprit du temps, il n'était plus possible pour Vincent de Beauvais de rédiger en 1256 une somme du savoir sans consacrer cet espace élargi à l'étude de la nature.

Dans le catalogue alphabétique des pierres, ce sont les encyclopédistes qui deviennent les autorités principales : Solin, Thomas, Arnold, mais aussi Isidore et Pline, qui sont relus et plus largement cités que dans la version précédente. Des citations des Météorologiques d'Aristote et du pseudépigraphique De vegetabilibus s'ajoutent à ce matériel, ainsi que des extraits des Aluns et sels de Rhazès. Cependant, l'apport principal du livre VIII est le Liber lapidum de Marbode, dont les vers illustrent chacune des notices du calatogue alphabétique sous le marqueur in lapidario, utilisé pour un même contenu chez Barthélemy l'Anglais.

Il faut signaler par ailleurs l'existence, dès la version bifaria du Speculum naturale, d'une source de documentation importante, mise à contribution sans toujours le signaler dans les chapitres sur les pierres (Vincent de Beauvais préférant donner comme marqueur de citation celui que sa source elle-même donnait, «sautant» ainsi l'indice d'une médiation dans la transmission). Il s'agit du Chronicon du trouvère puis moine cistercien Hélinand de Froidmont, resté en grande

${ }^{19}$ Liber apologeticus, c. 18 : Fateor ex mea parte meo iudicio professionis et intencionis mee modum excessi maximeque in eis que ex precepto Dei terra germinans protulit tercia die creacionis mundi. Cité par M. Paulmier-Foucart, «Étude sur l'état des connaissances au milieu du XIII ${ }^{\mathrm{e}}$ siècle » (op. cit.), p. 102. 
partie inédit. Il fut rédigé vers 1211-1223. À l'occasion d'un exposé sur le pectoral d'Aaron au chapitre X, Hélinand consacre trois chapitres $(55,56,57)$ à chacun des rangs de pierres qui l'ornent: De tribus lapidibus primi ordinis in rationali - De tribus secundi - De tribus tercii. Neuf pierres seulement rentrent donc en ligne de compte $^{20}$. Sa documentation, à en juger par les marqueurs, est très variée : elle s'alimente à l'Exode, à Théophraste, Simmaque, Flavius Josèphe, Virgile, Fulgence, Pline, Solin, Isidore, Raban Maur, mais aussi au Lapidarium, qui n'est autre que le lapidaire de Marbode. Un marqueur Evax rex Arabum induit la question de savoir s'il s'agit de Marbode ou bien du lapidaire extrapolé d'Evax-Damigéron. Il nous semble qu'il s'agit du second, pour autant qu'on puisse en juger par la courte notice offerte. Il n'est donc pas exclu qu'Hélinand ait disposé d'un lapidaire composite reprenant les dires de plusieurs lapidaristes, dont Théophraste ${ }^{21}$, comme le laisse croire la phrase suivante: Et in lapidario scriptum est Theofrastum de natura eius scripsisse quos tantum omnes auctores non dubium est Iheronimum legisse. D'autres petites notices sur les pierres interviennent à d'autres endroits dans le livre $\mathrm{X}$ du Chronicon. Elles rapportent les dires de Jérôme, Pline, Cicéron et Macer (c'est-àdire l'herbier de Macer floridus, un texte contemporain de Marbode de Rennes). Il nous paraît aussi que sous la variété des marqueurs se cache un intermédiaire principal: Pline, qui transmet lui aussi les informations de Théophraste et Simmaque, mais également celles de "Iuba», cet écrivain antique, naturaliste, qui réapparaît transformé sous le nom de Iorach chez Arnold de Saxe ${ }^{22}$. Chez Hélinand, Isidore apparaît une seule fois invoqué à propos des pierres, à propos de la topaze et de l'émeraude ${ }^{23}$. Il ne constitue donc pas pour Hélinand une source de référence pour les pierres.

Enfin, vers 1200-1210 également, un précoce encyclopédiste brittanique, Alexandre Nequam, avait déjà consacré quelques chapitres à la matière minérale dans un environnement documentaire assez semblable à celui des sources de Thomas de Cantimpré, quoique moins diversifié et à peu de choses près sans introduction de sources gréco-latines ou arabo-latines en traduction. Parmi les sources essentielles du De naturis rerum d'Alexandre Nequam, les Étymologies avaient déjà leur place. L'auteur a rassemblés ses informations sur la nature à partir de Pline, Solin, Solin, Cassiodore et Isidore de Séville, mais il emprunte aussi, sans

\footnotetext{
${ }^{20}$ Nous avons publié les notices sur les pierres d'Hélinand dans les annexes à l'article $L a$ science encyclopédique des pierres (op. cit.).

${ }^{21}$ R. Halleux, éditeur du lapidaire de Damigéron-Evax, a montré que certains témoins manuscrits entremêlaient la matière d'extraits de Théophraste.

${ }^{22}$ Cf. I. Draelants, «Le dossier des livres sur les animaux et les plantes de Iorach : tradition occidentale et orientale », Occident et Proche-Orient : contacts scientifiques au temps des croisades. Actes du Colloque de Louvain-la-Neuve, 24-25 mars 1997, éd. I. Draelants - A. Tihon - B. Van den Abeele, Louvain-la-Neuve - Turnhout, 2000, p. 191-276.

${ }^{23}$ Chronicon, Livre X,54; ms. Città del Vaticano, B.A.V., Regin. lat. 535f. 246a : X, c. 55. De tribus lapidibus primi ordinis in rationali: (Isidorus in libro ethim. XVI) Ysidorus autem dicit trogoditas predones cum in arabia fessi fame herbam effunderent eum eruisse deinde cum eadem insula nebulis operta quereretur tandem a nauigantibus inuenta est et id sic dicta qui trogodite topaz in querere dicunt. Smaragdius autem ut in eodem legitur xii habet species sed scithici meliores sunt quos a grifibus rapiunt ariomapsi.
} 
les nommer, à Aristote et à Dioscoride, non sans ajouter des commentaires et anecdotes personnelles. Pline, Solin et Isidore sont aussi les sources de sa description des minéraux aux chapitres 50 et 51 , celle des métaux aux chapitres 52 à 55 et celle des pierres aux chapitres 85 à 98 . Ces chapitres interviennent à l'intérieur de la description de l'élément terre, au livre II, où sont traités les minéraux suivants : 50. De carbone, 51. De calce, 52. De metallis, 53. De auro, 54. De ferro, 55. De vivo argento, 85. De lapidibus achate et medicon, 86. De asbesto, 87. De chelidonio, 88. De magnete, 89. De lapide qui allectorio dicitur, 90. De beryllo, 91. De smaragdo, 92. De adamante, 93. Idem de adamante, 94. De adamante et magnete, 95. De galactite, 96, De crystallo, 97. De gagate. Le dernier chapitre traite de la vertu d'attraction.

Alexandre Nequam ne semble avoir utilisé ni un lapidaire chrétien, ni le Liber lapidum en vers de Marbode. La notice sur l'asbeste provient d'Isidore. Celles concernant l'aimant, la magnétite, la galactite, le cristal et l'agate sont inspirées en grande partie des Collectanea rerum memorabilium de Solin. Une comparaison trahit aussi une influence de la Materia medica de Dioscoride, pour achates et medicon, qui n'est autre que le medus chez les autres encyclopédistes, comme pour la chélidoine, l'alectoire et le béryl. Cet usage du lapidaire inclus dans la très célèbre pharmacopée de Dioscoride n'est pas étonnant dans la mesure où il est avéré qu'Alexandre Nequam, probablement formé comme médecin - d'après son propre témoignage ${ }^{24}-$ a eu également des contacts avec la médecine salernitaine ${ }^{25}$.

\subsection{L'EXEMPLE DE L'AIMANT}

L'influence des Étymologies à travers le temps et le cumul systématique de la compilation encyclopédique peut aussi être observée grâce à l'exemple de l'aimant, un minéral traité chez tous les encyclopédistes, de manières diverses, en raison de sa fascinante vertu attractive. L'information d'Isidore à ce propos prolonge celle apportée par Pline l'Ancien et se pérennise chez la plupart des encyclopédistes du $\mathrm{XIII}^{\mathrm{e}}$ siècle. Ci-dessous, nous proposons un tableau comparatif des informations sur l'aimant et la magnétite chez les encyclopédistes, en rapport avec l'origine de leurs données.

Vincent de Beauvais consacre dans son Speculum naturale plusieurs notices au diamant et à l'aimant. Dans le tableau ci-dessous, nous n'incluons pas les passages qu'il a tirés textuellement du Liber de natura rerum de Thomas de Cantimpré et du Liber Lapidum en vers de Marbode, ni les extraits de Pline l'Ancien, Naturalis historia, ou des Étymologies d'Isidore de Séville identifiés nommément par un marqueur de référence. Arnold de Saxe, en dehors de son catalogue alphabétique des pierres (partie III du De floribus rerum naturalium),

${ }^{24}$ De laudibus divinae sapientiae, éd. Th. Wright, p. 503 : Hic artes didici docuique fideliter, inde / Accessit studio lectio sacra meo. / Audivi canones, Hippocratem, cum Galieno, / Ius ciuile mihi displicuisse neges. I

${ }^{25} \mathrm{Cf}$. A. Birkenmajer, «Le rôle joué par les médecins et les naturalistes dans la réception d'Aristote au XII ${ }^{\mathrm{e}}$ et au XIII ${ }^{\mathrm{e}}$ siècles ", La Pologne au VI congrès international des sciences historiques, Oslo, 1928, Varsovie, 1930, p. 1-15, ici p. 4 ; B. Lawn, The Salernitan Questions. An Introduction to the History of Mediaeval and Renaissance Problem Literature, Oxford, 1963 , p. 32, 44-45 et 64 . 
ajoute au chapitre 8 de la quatrième partie des propriétés liées à l'attraction qu'il a trouvées chez Aristote. Ces informations ont ensuite été incorporées par Vincent de Beauvais et par Albert le Grand dans les notices de leur lapidaire alphabétique, mais nous ne les incluons pas dans le tableau qui suit. La présence d'Arnold de Saxe dans ce tableau ne se justifie pas par des citations explicites d'Isidore, exclues dans son œuvre puisqu'il avait décidé de ne citer que les philosophi moderni. Cependant, bien qu'Arnold ait négligé nombre d'auteurs vénérables, il faut noter que des informations de Pline et d'Isidore ont traversé le temps pour se retrouver dans son texte, par l'intermédiaire de l'utilisation d'une version de Marbode. De la même manière, s'y est immiscé le lapidaire de Damigéron-Evax.

\begin{tabular}{|c|c|c|}
\hline \multirow{2}{*}{$\begin{array}{c}\text { Propriétés } \\
\text { et autorités chez qui on les trouve }{ }^{26}\end{array}$} & \multicolumn{2}{|l|}{ adamas } \\
\hline & \begin{tabular}{|c|} 
diamant \\
\end{tabular} & magnétite \\
\hline $\begin{array}{l}\text { Ne se trouve que dans une quantité plus petite qu'une } \\
\text { noisette (Solin, Isidore, Marbode) }\end{array}$ & TC, XIV, 4 & \\
\hline Est très dur (Isidore, Marbode) & $\begin{array}{l}\text { TC, XIV, } 4 \text {; AG, Min. II, } \\
\text { II, } 1\end{array}$ & \\
\hline A la couleur du cristal (Marbode) & TC, XIV, 4 ; AG, Min. II, I & $\mathrm{I}, 1$ \\
\hline $\begin{array}{l}\text { A une couleur plus sombre que le cristal (Marbode, } \\
\text { pour une deuxième espèce) }\end{array}$ & & $\begin{array}{l}\text { AS, III, I, 3; } \\
\text { VB, VIII,39 }\end{array}$ \\
\hline $\begin{array}{l}\text { Ne peut etre «vaincu» par le fer (ni par le feu) } \\
\text { (Isidore, } \quad \text { Solin, } \\
\text { mais se rompt sous l'action (du vinaigre et) du sang (et } \\
\text { de la chair) de bouc (Pline, Solin, Isidore) }{ }^{27}\end{array}$ & $\begin{array}{l}\text { AN, } 92 ; \text { TC, XIV, 4; } \\
\text { AG, II, II, } 1\end{array}$ & $\begin{array}{l}\text { AS, III, I, 3; } \\
\text { VB VIII, } 39\end{array}$ \\
\hline est supérieur aux autres pierres venues d'Inde (Solin) & $\mathrm{AN}, 93$ & \\
\hline se trouve sur les rives cristallines de l'Inde & TC, XIV, 4 & \\
\hline $\begin{array}{l}\text { convient aux lymphatiques/lunatiques, (Pline/Solin) } \\
\text { et aux possédés }\end{array}$ & AN, 93 & TC, XIV, 4 \\
\hline résiste au poison (Solin, Dioscoride, Marbode) & $\begin{array}{l}\text { AN, 93; TC, XIV, 4; As } \\
\text { VIII, } 39\end{array}$ & III, I, 3 ; VB \\
\hline Se trouve en plus grande quantité (qu'une noisette) & & $\begin{array}{l}\text { TC, XIV, 4; } \\
\text { AS III, I, 3, } \\
\text { AG, II, II, 1 }\end{array}$ \\
\hline
\end{tabular}

\footnotetext{
${ }^{26}$ Nous n'avons fait figurer que les autorités susceptibles d'avoir été utilisées par les encyclopédistes dont nous parlons. AS = Arnold de Saxe, AG = Albert le Grand, De mineralibus, $\mathrm{TC}=$ Thomas de Cantimpré, $\mathrm{BA}=$ Barthélemy l'Anglais.

${ }^{27}$ Albert le Grand ajoute que le procédé fonctionne mieux encore si le bouc a ingéré du vin, du petrosillum et du siler montanum, puisque qu'un tel sang de bouc sert aussi à casser les calculs de la vésicule. Ce commentaire semble de son cru, mais il est puisé à la tradition médicale. Référence à Pline: Historia naturalis, XXXVII, 57. Jérôme consacre aussi un chapitre pareil au diamant, où il mentionne quatre espèces très résistantes, qui se dissolvent dans le sang de bouc et sont les antidotes au poison (In amos, III, 7, éd. P.L., t. 25, col. 1124D). Il est probable que cette propriété physique soit trouvée dans Xénocrate d'Ephèse, un lapidariste $\mathrm{du} \mathrm{I}^{\mathrm{er}}$ siècle à qui Pline doit probablement le catalogue alphabétique des gemmes qui se trouve à la fin du livre XXXVII (139-185).
} 


\begin{tabular}{|c|c|c|}
\hline $\begin{array}{l}\text { Vient d'Arabie, de Chypre et de Ferrare (Solin, } \\
\text { Marbode) }\end{array}$ & & $\begin{array}{l}\text { TC, XIV, } 4 ; \\
\text { AS III, I, 3; } \\
\text { AG, II, II, 1 }\end{array}$ \\
\hline Pénètre le plomb, le fer & AG, II, II, 1 & AS III, I, cit 3 \\
\hline Entame les pierres précieuses & TC, XIV, 4 ; AG, II, II, 1 & \begin{tabular}{|lr} 
AS III, I, \\
$3 ; \mathrm{VB}$ VIII, 39 \\
\end{tabular} \\
\hline 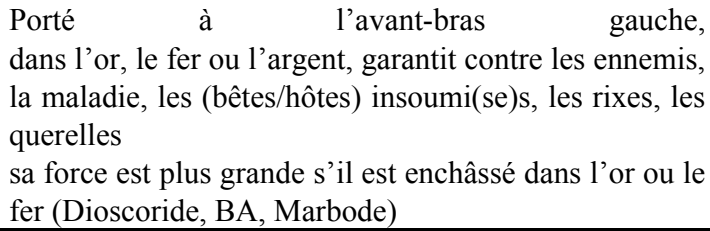 & $\begin{array}{lll}\text { AG, } \quad \text { II, } \quad \text { II, } & 1^{28} \\
\text { TC, } \quad \text { XIV }, & 4 \\
\text { BA, } & \text { XVI, } 9\end{array}$ & $\begin{array}{l}\text { TC, XIV, } 4 ; \\
\text { VB, VIII, } 39 \\
\text { AS, III, I, } 3 ; \\
\text { BA, XVI, } 9\end{array}$ \\
\hline
\end{tabular}

\begin{tabular}{|c|c|c|c|}
\hline \multicolumn{2}{|l|}{ Propriétés } & \multicolumn{2}{|c|}{ Magnes } \\
\hline \multicolumn{2}{|c|}{$\begin{array}{l}\text { Augmente la grâce et la persuasion et la faculté de } \\
\text { discerner (Diosc. BA, Marbode) }\end{array}$} & \multicolumn{2}{|c|}{ AS, III, I, 53, BA XVI, 43} \\
\hline \multicolumn{2}{|c|}{$\begin{array}{l}\text { Broyé et mêlé à du lait, soigne l'hydropisie } \\
\text { (*Dioscoride : } \mathrm{VB}, \mathrm{BA}, \mathrm{Marbode)} \\
\text { ainsi que la mélancolie et l'alopécie (Platearius, De } \\
\text { simplici medicina: VB) }\end{array}$} & \multicolumn{2}{|c|}{$\begin{array}{l}\text { TC, XIV, } 45 \text {; AG, II, II, } 11 \text {; VB, VIII, } \\
21 \\
\text { AS, III, I, } 53 \text {; VB, VIII, } 21 \text {; BA XVI, } \\
43\end{array}$} \\
\hline \multicolumn{2}{|c|}{ En poudre, soigne les brûlures $(*$ Dioscoride, Marbode) } & \multicolumn{2}{|c|}{ TC, XIV , 45; VB VIII, 21} \\
\hline \multicolumn{2}{|c|}{$\begin{array}{l}\text { Se trouve chez les Troglodytes et en Inde (*Dioscoride } \\
\text { VB, Isidore, Marbode) }\end{array}$} & \multicolumn{2}{|c|}{$\begin{array}{l}\text { TC, XIV, } 45 \text {; AS, III, I, } 53 \text {; AG, II, II, } \\
11 ; \mathrm{VB}, \mathrm{VIII}, 21 \text {; BA, XVI, } 43\end{array}$} \\
\hline \multicolumn{2}{|c|}{$\begin{array}{l}\text { Se trouve en mer d'Inde, où il est difficile de naviguer } \\
\text { avec des bateaux munis de clous (Galien, De } \\
\text { lapidibus } ?^{29} \text { ) }\end{array}$} & \multicolumn{2}{|c|}{ VB, VIII, 21 ; AG, II, II, 11} \\
\hline \multicolumn{2}{|c|}{ Attire le verre comme le fer } & \multicolumn{2}{|l|}{ TC, XIV, 45} \\
\hline & diamant & \begin{tabular}{l|l} 
& magnétite \\
\end{tabular} & aimant \\
\hline $\begin{array}{l}\text { Eloigne les craintes (Pline/Solin) / } \\
\text { rêves vains /fantômes / incubes } \\
\text { (Dioscoride, Marbode) }\end{array}$ & AN, 93 & $\begin{array}{l}\text { TC, XIV, } 4 ; \\
\text { AS, III, I, cit. } \\
3 ; \text { VB, VIII, } \\
39\end{array}$ & AG, II, II, 11 \\
\hline $\begin{array}{l}\text { Posé sur lui, empêche que le magnes } \\
\text { n'attire le fer (Isidore, Marbode) } \\
\text { Soustrait le fer à l'attraction du }\end{array}$ & $\begin{array}{l}\text { AN, } 94 ; \mathrm{AS}, \\
\text { II, II, } 1 ; \\
\text { AN, } 94 ; \mathrm{TC},\end{array}$ & $\begin{array}{l}\text { III, I, cit. } 3 ; \text { AG, } \\
\text { VB, VIII, } 39 \\
\text { XIV, } 4 ; \mathrm{AG}, \mathrm{II}, \mathrm{II},\end{array}$ & $\begin{array}{lll}\text { II, } & \text { II, } & 11\end{array}$ \\
\hline
\end{tabular}

${ }^{28}$ Les métaux sont l'or, l'argent ou le « chalybe » (acier) chez Albert le Grand.

${ }^{29}$ Cette attribution est donnée par Vincent de Beauvais. Nous pensons qu'il l'a tirée du De gradibus de Constantin, où l'on peut lire (éd. Opera omnia, Bâle, 1539, p. 342-87, ici p. 378) : Aristoteles dixit esse lapidem in ripa maris Indiae inuentum. Cuius natura calida et sicca in tertio gradu. Dixit etiam in libro de lapidibus quod nautae non audent transire cum naui ferreos clavos habente aut aliquod artificium ferri in ea ducere. Nave etiam illis montanis appropinquante, omnes clavi et quidquid ex ferro editum a montanis attrahitur cum proprietate quam habent. L'anecdote était donc présente dans l'original du De lapidibus «d'Aristote». 


\begin{tabular}{|c|c|c|c|}
\hline «magnes » (Isidore, Marbode) & \multicolumn{2}{|l|}{1} & \\
\hline Il attire le fer (Dioscoride, Marbode) & $\begin{array}{l}\text { n'attire pas } \\
\text { le fer }{ }^{30}: A G \text {, } \\
\text { II, II, 1 }\end{array}$ & $\begin{array}{l}\text { AN, } 98 ; \quad \text { TC, } \\
\text { XIV, } 4 ; \text { AS, III, } \\
\text { I, } 3 ; \text { VB VIII, } 39\end{array}$ & $\begin{array}{l}\text { AN, } 98 ; \text { TC, XIV, } \\
45 ; \text { AS, III, I, } 53 \text {; } \\
\text { AG, II, II, } 11\end{array}$ \\
\hline $\begin{array}{l}\text { Frottée à lui, une aiguille (de fer) } \\
\text { s'aimante } \\
\text { et s'oriente au nord }\end{array}$ & & TC, XIV, 4 & $\begin{array}{l}\text { AG, II, II, } 11 \\
\text { AN, 98 }\end{array}$ \\
\hline $\begin{array}{l}\text { Est favorable aux actes magiques (Isidore, } \\
\text { Marbode) }\end{array}$ & & TC, XIV, 4 & TC, XIV, 45 \\
\hline $\begin{array}{l}\text { A une couleur de fer/brillante (Isidore, } \\
\text { Marbode) }\end{array}$ & & $\begin{array}{l}\text { TC, XIV, 4; AS, } \\
\text { III, I, 3; VB, } \\
\text { VIII, } 39\end{array}$ & $\begin{array}{l}\text { TC, XIV, 45; AS, } \\
\text { III, I, 53; AG, II, II, } \\
11 ; \text { BA, XVI, 43 }\end{array}$ \\
\hline $\begin{array}{l}\text { Identifie l'épouse adultère si on la pose } \\
\text { sous/sur sa tête pendant son sommeil } \\
\text { (Dioscoride BA, Marbode) }\end{array}$ & BA, XVI, 9 & & $\begin{array}{l}\text { AN, } 88 ; \text { TC, XIV, } \\
45 ; \text { AG, II, II, } 1 ; \\
\text { BA XVI, } 9\end{array}$ \\
\hline $\begin{array}{l}\text { (ré)concilie les maris et les épouses } \\
\text { (Dioscoride BA, Marbode) }\end{array}$ & BA, XVI, 9 & & $\begin{array}{l}\text { TC, XIV, } 45 ; \mathrm{AS}, \\
\text { III, I, } 53 ; \mathrm{BA} \text { XVI, } \\
43\end{array}$ \\
\hline $\begin{array}{l}\text { Posé en lamelles sur des charbons aux } \\
\text { quatre coins de la maison, éloigne les } \\
\text { habitants, drogués par la fumée, et la rend } \\
\text { disponible aux voleurs (*Diosc. VB-BA, } \\
\text { Marbode) }\end{array}$ & & & $\begin{array}{l}\text { TC, XIV, 45; AS, } \\
\text { III, I, 53; AG, II, II, } \\
11 ; \text { BA XVI, 43; } \\
\text { VB VIII, } 21\end{array}$ \\
\hline
\end{tabular}

Les informations d'Isidore sur l'aimant et le magnes apparaissent donc fondues dans une documentation qui s'est accumulées en couches successives, tout en puisant continûment aux sources anciennes.

\section{Pour conclure sur la perrénité des Étymologies}

Isidore, déjà réduit à son rôle d'auteur des Étymologies, a vu, dans les encyclopédies naturelles du début du $\mathrm{XIII}^{\mathrm{e}}$ siècle, l'intérêt pour son œuvre se concentrer sur son apport dans le domaine de la connaissance de la nature. Mais même en cette matière, sa réception a évolué vers une diminution notable en faveur d'autres sources. Les Étymologies restent néanmoins une référence pour les naturalistes, mais à des titres divers: chez Vincent de Beauvais, dans la préoccupation de n'omettre aucune autorité. Chez Albert le Grand, commentateur philosophique plutôt qu'encyclopédiste, la matière isidorienne n'apparaît que dans les cas où, pour une information précise, elle a été transmise par des auteurs postérieurs dont les dires sont moins certains ou criticables; si l'information d'Isidore ne lui paraît pas présente ailleurs, Albert continue de s'y référer. Alexandre Nequam, Thomas de Cantimpré, Barthélemy l'Anglais reviennent encore de première main aux Étymologies avant 1240 , c'est-à-dire à l'époque de la première version (terminée en 1244) du Speculum maius, où la proportion des extraits

${ }^{30}$ Non trahit autem ferrum, eo quod sit proprius locus generationis eius, ut quidam mendose dixerunt. 
d'Isidore est encore très importante. Dans certains chapitres sur la mer, par exemple, un quart de l'information du Speculum naturale est tirée des Étymologies; dans celui des minéraux, c'est quarante pour cent de la documentation qui leur est encore empruntée. Plus de la moitié du texte des Étymologies est utilisée dans l'ensemble du Speculum. En revanche, dans la réécriture terminée en 1259, quand le naturale éclate en naturale et doctrinale, avec les extraits ajoutés d'auteurs " modernes », les Étymologies ne représentent plus qu'un dixième de l'information dans ces mêmes chapitres.

A travers les couches de sédimentation encyclopédique, l'autorité d'Isidore reste visible pendant des siècles dans les œuvres naturalistes souvent motivées par le souci de mener un travail de recherche et d'étude «utile» aux contemporains, comme les encyclopédies franciscaines et dominicaines de la première moitié du $\mathrm{XIII}^{\mathrm{e}}$ siècle. Cependant, sa documentation décline dans l'ensemble par rapport aux connaissances nouvelles que représentent les traductions d'œuvres d'Aristote et d'Avicenne, Albumasar, le De plantis d'Aristote, les Questiones naturales d'Adélard de Bath, la philosophia mundi de Guillaume de Conches, etc. Chez les encyclopédistes davantage orientés vers la science aristotélicienne, comme Arnold de Saxe, ce sont les philosophi moderni qui s'installent aux dépens d'Isidore et de Pline, et les Étymologies ne subsistent même plus comme la nécessaire référence à un modèle encyclopédique et naturaliste antérieur. Ce mouvement accompagne celui de l'enseignement universitaire, où les textes et commentaires sur les textes philosophiques et scientifiques nouvellement traduits forment un programme inédit par rapport à l'ancien quadrivium.

Par ailleurs, dans la plupart des lapidaires médiévaux jusque 1230 environ, tant que l'enquête sur la nature des compilateurs reste livresque, les Étymologies d'Isidore continuent d'être un répertoire naturaliste de référence, une source obligée. Cela, même quand d'autres textes qui l'ont déjà exploité, comme le Liber lapidum de Marbode de Rennes, sont utilisés comme source à part entière ou lorsque des œuvres traduites de l'arabe transmettent la Météorologie ou des bribes de la minéralogie d'Aristote chez les nouveaux travaux naturalistes du XIII ${ }^{\mathrm{e}}$ siècle. En revanche, Isidore n'est plus une source directe au moment du renouvellement de la connaissance des pierres qui démarre avec le De natura lapidum d'Arnold de Saxe (1230-40), et a fortiori dans le De mineralibus d'Albert le Grand (1245-63) qui s'en inspire très largement, revendique la méthode et l'information aristotéliciennes, et ajoute à des sources livresques traditionnelles et nouvelles l'apport de son observation et de son expérience.

Dans cette étude, nous nous sommes arrêtée en particulier sur la production didactique de la période la plus riche en encyclopédies latines : les deux premiers tiers du XIII ${ }^{\mathrm{e}}$ siècle. Au-delà de cette période, la postérité encyclopédique d'Isidore prend divers chemins, que ce soit via la réutilisation de ces encyclopédies du XIII siècle dans d'autres compilations encyclopédiques latines, ou dans leurs traductions adaptées en langues vulgaires, où le recours de première main de la documentation d'Isidore se poursuit néanmoins discrètement jusqu'au XVIII ${ }^{\mathrm{e}}$ siècle.

Isabelle Draelants

CNRS -Université de Nancy2 - Atelier Vincent de Beauvais 